\title{
THE STILLE REACTION, 38 YEARS LATER
}

\author{
Carlos Cordovilla, Camino Bartolomé, Jesús Mª Martínez-Ilarduya, Pablo Espinet* \\ IU CINQUIMA/Química Inorgánica, Facultad de Ciencias, Universidad de Valladolid, 47071-Valladolid (Spain)
}

Fax: (+)34 983 423013.e-mail: espinet@qi.uva.es. web: http://gircatalisishomogenea.blogs.uva.es/

\begin{abstract}
The first now named Stille reaction was published 38 years ago, and the last comprehensive revision of this catalysis was in 2004. Since then the knowledge of the different steps of the three possible (and sometimes competing) reaction pathways (cyclic, open, and ionic) has been almost completed by synergistic experimental and theoretical studies: the Stille reaction is perhaps the best characterized catalytic process if we consider the number of intermediates that have been detected. This review concentrates on the mechanistic new knowledge, and on important aspects as the revolution with the use of bulky phosphines, the bimetallic alternative of the Stille reaction, the enantioselectivity in Stille and palladium free Stille processes, the meaning of copper effect, or the possible approaches to make Stille coupling a greener process.
\end{abstract}

KEYWORDS: Stille cross-coupling, reaction mechanism, transmetalation, palladi-

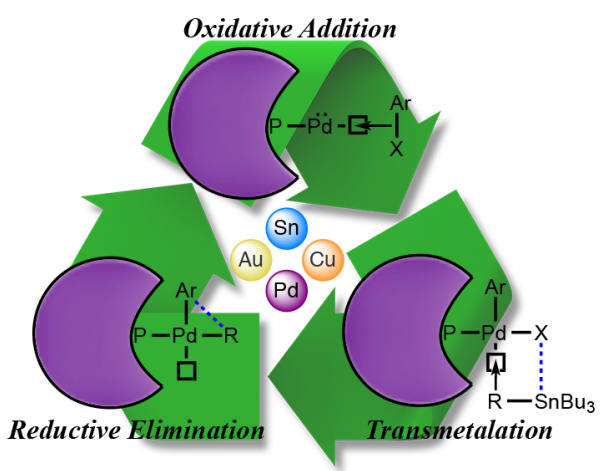
um, tin.

\section{Introduction}

The cross coupling reaction of organic electrophiles with organostannanes (Eq. 1) is traditionally known as the Stille reaction. The first examples of the coupling, published by the groups of Eaborn ${ }^{1}$ and Kosugi-Migita, ${ }^{2}$ preceded the first report on the topic by Milstein and Stille, ${ }^{3}$ but the synthetic works of Stille since 1978, and his amazingly modern mechanistic studies on the different steps involved in the catalytic cycle, merit that the reaction is identified with his name. Were it not for his premature death at the age of 59, in a flight crash, ${ }^{4}$ John Kenneth Stille would have likely shared the 2010 Nobel Prize in Chemistry for "work on palladium-catalyzed cross-coupling reactions. ${ }^{5}$

$$
\mathrm{R}^{1}-\mathrm{X}+\mathrm{R}^{2}-\mathrm{SnR}_{3} \stackrel{[\mathrm{Pd}]}{\longrightarrow} \mathrm{R}^{1}-\mathrm{R}^{2}+\mathrm{SnR}_{3}-\mathrm{X}
$$

The understanding of the mechanism, which shares common steps with other palladium-catalyzed cross-coupling reactions, progressed fast in the hands of Stille and the review he published in 1986 presented and discussed a four-step cycle including sequential oxidative addition, transmetalation, isomerization, and reductive elimination processes, ${ }^{6}$ as well as the proposal that transmetalation of chiral fragments occurred with inversion of configuration. In 2004 Espinet and Echavarren published a major critical actualization of the Stille reaction mechanisms, in which each step was considered and discussed. ${ }^{7}$ The mechanism had gained complexity due to the proposal of two transmetalation pathways (open and cyclic), to account for the observation of inversion and, respectively, retention of configuration in the transmetalation step. ${ }^{8}$ An additional third pathway accounting for transmetalations via cationic species was also considered. ${ }^{9,10}$ The change of paradigm considering several mechanisms rather than only one is still the major mechanistic change from the early proposals, and remains a useful map of the territory nowadays. In the time elapsed since our review in 2004 several others have appeared, usually included in a more general cross-coupling context. These are given in the references. ${ }^{11,12,13}$

The Stille reaction is now 38, a critical age for human beings. How is it for the reaction? In this review we try to offer a critical non-exhaustive analysis of the main advances and interesting aspects since our 2004 review, concentrating on key changes and trying to comment on some practical aspects in view of the complexities of the reaction.

\section{Is the Stille reaction still an option?}

The rapid evolution of other alternative Pd-catalyzed crosscouplings sets the question whether the Stille reaction is still useful and competitive. ${ }^{14}$ As an advantage, the Stille reaction is a mild process that tolerates a wide variety of functional groups and for this reason it is frequently used in the synthesis of molecules of high complexity. Furthermore, organostannanes are relatively insensitive to moisture and oxygen, allowing for harsher reaction conditions, and are accessible by nu- 
merous methods. However, the reaction adds, to the Pd concerns, that of potential Sn contamination. The problem is probably exaggerated from a strictly chemical point of view, since the toxicity of the more commonly used tri- $n$-butyltin derivatives $\left(\mathrm{LD}_{50}\right.$ in the range $\left.100-300 \mathrm{mg} \mathrm{kg}^{-1}\right)$ is far lower than those of triethyl- and trimethyl-tin derivatives $\left(\mathrm{LD}_{50}<15\right.$ $\left.\mathrm{mg} \mathrm{kg}^{-1}\right),{ }^{15}$ but it cannot be ignored, particularly for its use in the production of pharmaceuticals. The required upper limit of Sn level by toxicologists is about 20 ppm. ${ }^{16}$

In this respect it is interesting to recall the results of a study at Pfizer looking for a large-scale preparation of imidazolethienopyridine VEGFR kinase inhibitor for pharmaceutical purposes. ${ }^{17}$ The key step was the coupling of the imidazole and thienopyridine fragments composing the chloropyridine intermediate shown in Figure 1. Different cross-coupling processes were attempted but only the Stille coupling was suited to provide a robust and scalable cross-coupling method. The authors commented on a very important but often forgotten issue: "This suggests that the wide variety of cross-coupling methods demonstrated on simpler biaryl systems is more limited when applied to complex heterocyclic systems." Or, could we add, when the syntheses have to be scaled.

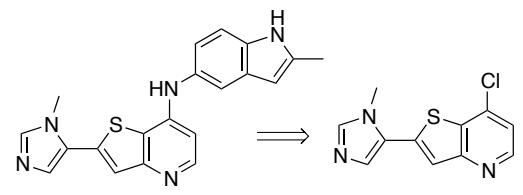

Figure 1. Retrosynthetic analysis of an imidazole-thienopyridine VEGFR kinase inhibitor through a chloropyridine key intermediate obtained by Stille coupling.

In the same line, the comparison of the Negishi, Suzuki, and Stille methods for the synthesis of halogenated 2chlorobithiazoles (Figure 2) showed that the Stille reaction was the best cross-coupling method. ${ }^{18}$ The Negishi method suffered from substantial side reactions leading to inseparable mixtures of products, and the Suzuki catalysis gave poor conversions.

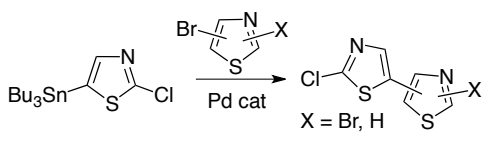

Figure 2. Synthesis of bithiazoles using Pd-catalyzed reactions where Stille is superior to Negishi and Suziki couplings.

Compared to $\mathrm{B}$ or $\mathrm{Zn}$ derivatives, the lower polarity (hence lower basicity) and higher steric demand of $\mathrm{Sn}$ derivatives makes them less nucleophilic and less reactive. However, nucleophilicity is not the only virtue sought for in a nucleophilic reagent: Reactivity and selectivity are often in conflict, ${ }^{19}$ and selectivity is a must in many areas of synthesis. Stille coupling has its own position in cross-coupling catalysis. This is supported by a recent estimation of the total number of publications and patents on cross-coupling reactions through 2010/April 2014, ${ }^{20}$ which affords the following scores and trend: Suzuki-Miyaura, 10175/15883 > Heck, 4029/5816 > Sonogashira, 3623/5689 > Stille, 2380/3537 > Negishi, 429/737 > Buchwald-Hartwig, 253/498 > Kumada-Corriu, 136/298 > Hiyama: 91/172 > Carbonyl $\alpha$-arylation, 113/193.

\section{The mechanisms: experimental and theoretical studies}

Chemistry occurs as a competition of possible reaction pathways, whether desired or undesired, which afford more or less selective processes as a result of the competition of rates of the pathways kinetically feasible. In the simple representation of the Stille cycle often found in books (Scheme 1), the Stille process, deprived of coordination information at $\mathrm{Pd}$, is comprised of three steps: oxidative addition, transmetalation, and reductive elimination. It looks as simple and selective as the subway map of Sevilla (Spain): there is only one line and you can hardly make mistakes (Figure 3 ). However, the true complexity of the Stille reaction reminds better the subway maps of New York, Madrid, Paris, or Moscow, and as a difference with using the subway transport, you have to make your catalytic trip with blind eyes, because you hardly see any signs. It is not that easy to take the right train, change trains at the right point, and drop at the chosen station.

\section{Scheme 1. A Simplified Stille Cycle}
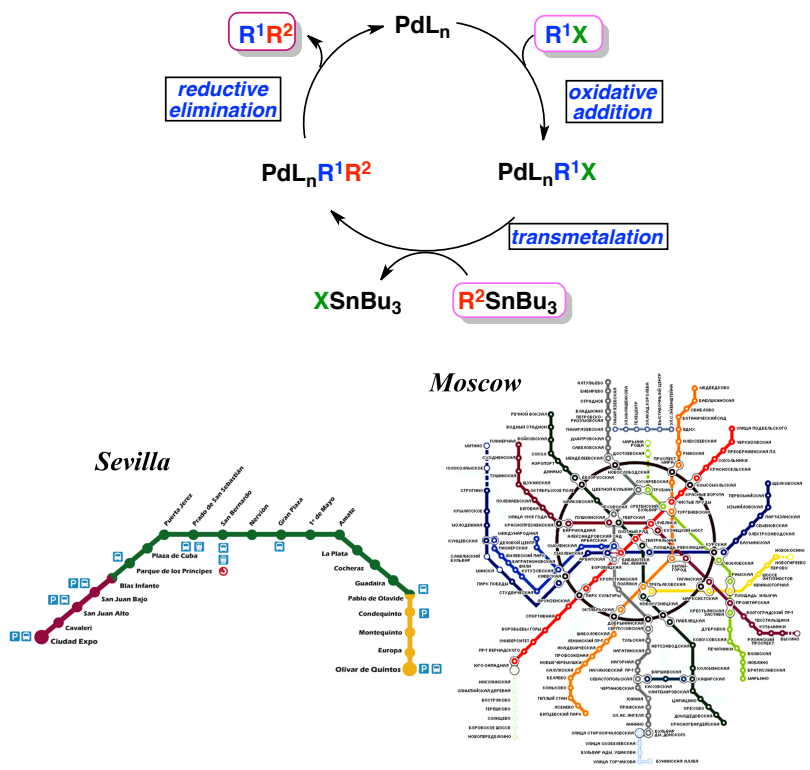

Figure 3. Maps of the subway transport. Left: Sevilla (Spain); right: Moscow (Rusia).

This complexity is reflected in the Stille cycle shown in Scheme 2, still a poor representation of reality but at least showing three important concepts sometimes forgotten: $i$ ) It is the transition metal catalyst that makes the job, obeying the rules of coordination chemistry. Ignoring coordination chemistry is like walking in a desert without a compass. ii) A fourth type of process, isomerization, has to be considered where appropriate, as highlighted in Scheme 2, and also others like ligand dissociation and ligand substitution. iii) Although not shown in Scheme 2, some steps in the cycle are easily reversible, which can give rise to undesired byproducts, particularly when the irreversible $\mathrm{C}-\mathrm{C}$ coupling step closing the cycle is too slow, allowing to generate new species via undesired (mistaken) reversible transmetalations.

It is interesting to warn that the cyclic and open pathways are part of the common mechanistic jargon in the literature, but the third pathway that we included from the beginning, the ionic pathway, is often disregarded and should be kept in mind when choosing solvents. The ionic pathway is in fact the most frequent subcategory of the open pathway (which can however proceed also through neutral species) and it is being highlighted because of its importance. We will see the importance of 
the open ionic pathway later on, in the section Stereoselectivity of Transmetalation: Inversion vs. Retention.

\section{Scheme 2. A More Detailed Stille Cycle}

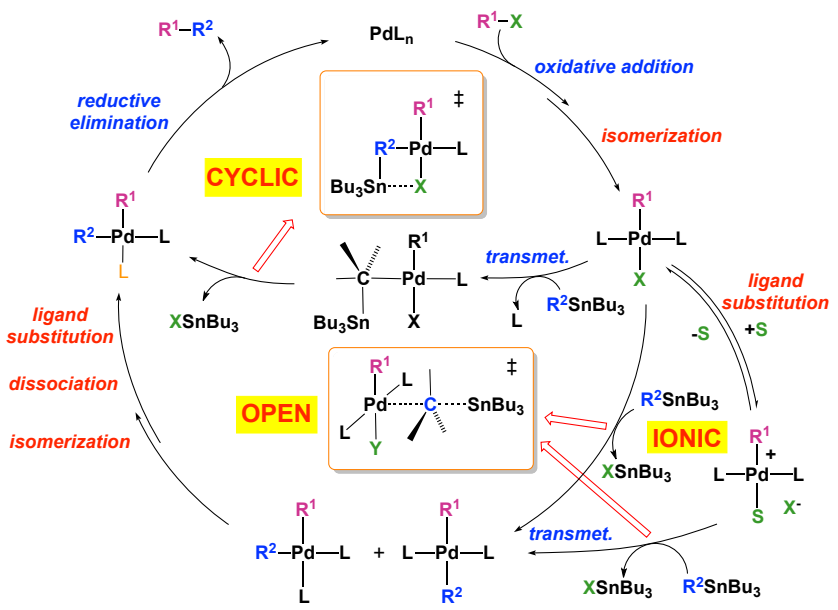

Comparing Scheme 2 with the cycle proposed in our 2004 review, based only on kinetic studies and observation of some intermediates, it is clear that the 2004 cycle remains essentially complete and correct, except for some details. Since then, our own DFT studies, using $\mathrm{Ph}-\mathrm{Br}$ and $\mathrm{Me}_{3} \mathrm{Sn}-\mathrm{CH}=\mathrm{CH}_{2}$, confirmed the open and cyclic transmetalation pathways proposed, although correcting the structure of the transition state for the cyclic pathway. ${ }^{21}$ We had proposed initially a concerted structure with penta-coordinated Pd on which formation of the square transmetalation fragment and $\mathrm{L}$ substitution took place simultaneously, ${ }^{8}$ but the computational study, did not find that proposed TS, and instead it supported that, at least for the transmetalation of vinyl, transmetalation occurs in two steps: ligand substitution by the entering vinyl group (using the double bond as the entering ligand), followed by transmetalation through the TS shown in Scheme 2. The two cyclic pathways, via the old $\mathbf{T S}^{7,8}$ or the new TS (here), have the same kinetic dependences and this case illustrates the convenience of combining calculations and experiment in mechanistic studies for a more accurate interpretation of the data. Other mechanistic DFT studies, ${ }^{22,23}$ some of them involving heterostannanes $\left(\mathrm{Me}_{3} \mathrm{SnZR}_{3}, \mathrm{Z}=\mathrm{P}, \mathrm{As} ; \mathrm{R}=\mathrm{Ph}, \mathrm{Me}\right)$ as nucleophiles, also support the validity of the mechanistic proposal in Scheme $2 .{ }^{24,25}$ It is, however, important to recall that DFT studies should never replace the primary value of experimental kinetic studies, as the precision of calculated energies cannot be guaranteed. An error in the calculated activation energy of $1 \mathrm{kcal} \mathrm{mol}^{-1}$, which looks unavoidable for metal-containing molecules, means roughly a one power of ten error in the corresponding reaction rate, which can dramatically change the prediction of the preferred pathway. ${ }^{26}$

Study of the retro-transmetalation reaction in Scheme 3, combining kinetic experiments and monitoring by ${ }^{19} \mathrm{~F}$ NMR spectroscopy with DFT calculations, has provided definitive additional confirmation of the cyclic mechanism. ${ }^{27}$ The complex $\left[\mathrm{PdRf}_{2}\left(\mathrm{AsPh}_{3}\right)_{2}\right]\left(\mathrm{Rf}=3,5-\mathrm{C}_{6} \mathrm{Cl}_{2} \mathrm{~F}_{3}\right)$ reacts with $\mathrm{Bu}_{3} \mathrm{SnI}$ to produce $\left[\mathrm{PdRfI}\left(\mathrm{AsPh}_{3}\right)_{2}\right.$ ] and $\mathrm{Bu}_{3} \mathrm{SnRf}$. The Stille reaction is the opposite sense reaction ending with $\mathrm{Rf}-\mathrm{Rf}$ coupling, but this coupling has a high activation energy for fluorinated aryls and does not take place.
This coupling frustration allows for several interesting observations: $i$ ) the reaction in Scheme 3 proceeds smoothly, confirming that the transmetalation step is, as expected, reversible; $i$ ) the Stille transmetalation (from the initial reagents to $\left.\left[\operatorname{PdRf}_{2} \mathrm{~L}_{2}\right]\right)$ is counter-thermodynamic $(\mathbf{3}+\mathbf{4}$ is more stable than $\mathbf{1 + 2}$ ), and for this reason it needs the irreversible coupling step to take place so as to make the overall process thermodynamically favorable; iii) a slow reductive elimination step can be rate determining (or, as in this case, frustrate the coupling): this is an important complication as commented above, because slow coupling will propitiate formation of undesired byproducts from undesired mistaken group exchanges in the reversible transmetalation. This explains, for instance, the observation of $\mathrm{Bu}_{3} \mathrm{SnPf}\left(\mathrm{Pf}=\mathrm{C}_{6} \mathrm{~F}_{5}\right.$ ) in the Stille coupling of PfI and $\mathrm{Bu}_{3} \mathrm{Sn}($ vinyl $\left.) ;^{9} i v\right)$ monitoring the retrotransmetalation allows for experimental observation of the intermediate complex $\left[\mathrm{PdRf}_{2}\left(\mathrm{AsPh}_{3}\right)\left(\mathrm{ISnBu}_{3}\right)\right](\mathbf{I 1})$, which precedes the rate determining state in the retro-Stille evolution and becomes observable.

\section{Scheme 3. The Retro-Stille Transmetalation Step}

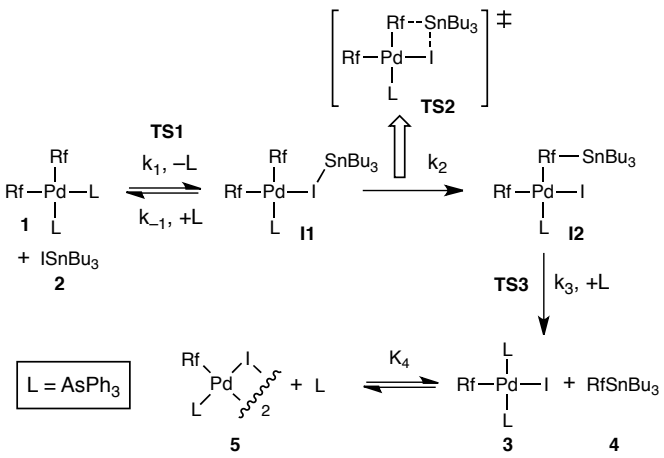

All the rate and equilibrium constants were determined and, along with DFT calculations provided the energy profile and the structures of the TS's in Figure 4. Note that theoretical values are $\Delta \mathrm{E}^{\ddagger}$ and do not match the experimental $\Delta \mathrm{G}^{\ddagger}$ values when there is important entropic contribution. Complex I1 is the result of ligand substitution of $\mathrm{AsPh}_{3}$ by $\mathrm{Bu}_{3} \mathrm{SnI}$ as entering ligand, and it is the first step to form the cyclic TS2.

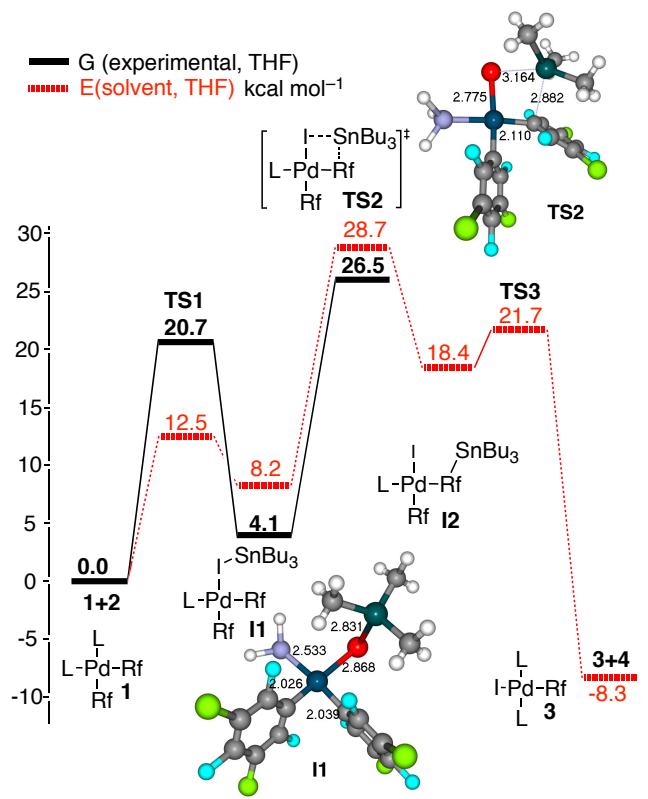


Figure 4. Profile of the retrotransmetalation reaction $1+2$, showing experimental $\Delta \mathrm{G}$ values in $\mathrm{THF}$ and calculated $\Delta \mathrm{E}$ values (solvent) in $\mathrm{kcal} \mathrm{mol}^{-1}$. The calculated structures of the detected intermediate $\mathbf{I 1}$ and the transmetalation transition state TS2 are also given.

With the addition of this study, the cyclic and open mechanisms are very well supported experimentally. In fact there are now physical observations of: cis- and trans-[PdR $\left.{ }^{1} \mathrm{XL}_{2}\right]$ products of oxidative addition (which immediately precede the cyclic or open transmetalation $\mathrm{TS}) \dot{ }^{8}\left[\mathrm{PdR}^{1} \mathrm{R}^{2} \mathrm{~L}\left(\mathrm{XSnBu}_{3}\right)\right]$, formed immediately after transmetalation; ${ }^{27}$ cis- $\left[\mathrm{PdR}^{1} \mathrm{R}^{2} \mathrm{~L}_{2}\right]$, formed when the $\left(\mathrm{Bu}_{3} \mathrm{SnX}\right)$ byproduct is liberated from $\mathrm{Pd}$ by substitution with an entering ligand; ${ }^{9}$ and trans- $\left[\mathrm{PdR}^{1} \mathrm{R}^{2} \mathrm{~L}_{2}\right]$, formed in competition with its $\mathrm{cis}$ isomer in reactions following the open pathway. ${ }^{9,10}$ It is very unusual that a mechanistic proposal is supported by so many physical observations.

At the time of our initial proposal of the cyclic and open mechanisms, the Stille experiments we studied started with the oxidative addition of a fluoroaryl iodide, which gives initially cis-[PdR $\left.\mathrm{IL}_{2}\right]{ }^{28}$ and our system happened to have a cis-trans isomerization of the oxidative addition product which was fast compared to the transmetalation rate of the next step, so the transmetalation was studied only on the trans-[PdR $\left.{ }^{1} \mathrm{IL}_{2}\right]$ complex. However, in a general case the oxidative addition can give cis or trans complexes, or a mixture of both (aryl halides give concerted cis oxidative addition, but alkyl halides often give directly trans complexes). The isomerization of these products can be slower or faster, or fall in the order of rate of the transmetalation, ${ }^{29}$ and in this case the coexistence of transmetalations on cis and on trans oxidative addition complexes, as well as the cis or trans stereochemistry of the transmetalation itself in the open mechanism, complicate the picture: The cycle in Scheme 2 should be multiplied by two, one starting from the cis and another from the trans oxidative addition complex.

These complications have in fact been observed in the study of the coupling of RfI with $\mathrm{Bu}_{3} \mathrm{SnC} \equiv \mathrm{CPh}$ : The cis- and trans$\left[\operatorname{PdRfI}\left(\mathrm{PPh}_{3}\right)_{2}\right]$ isomers were observed when monitoring the reaction regardless of the election of $\mathbf{1}$ or $\mathbf{2}$ as initial catalyst. Independent catalytic studies starting separately on each of them revealed the evolution of their isomerization, and the occurrence of transmetalations on both of them, which produced both isomers cis and trans- $\left[\mathrm{PdRf}(\mathrm{C} \equiv \mathrm{CPh})\left(\mathrm{PPh}_{3}\right)_{2}\right]$, as seen in Figure 5 for one of the monitored processes. Cis$\left[\mathrm{PdRf}(\mathrm{C} \equiv \mathrm{CPh})\left(\mathrm{PPh}_{3}\right)_{2}\right]$ is not observed because it undergoes very fast $\mathrm{C}-\mathrm{C}$ coupling to give $\mathrm{Rf}-\mathrm{C} \equiv \mathrm{CPh}$ (which is observed $)$, but trans- $\left[\mathrm{PdRf}(\mathrm{C} \equiv \mathrm{CPh})\left(\mathrm{PPh}_{3}\right)_{2}\right]$ cannot couple and it accumulated in solution due to a extremely slow isomerization to cis. Thus the trans complex became a Pd trap that progressively captured the catalyst in that inactive form and eventually stopped the process preventing to obtain good yield of the desired product $\mathrm{Rf}-\mathrm{C} \equiv \mathrm{CPh}$.

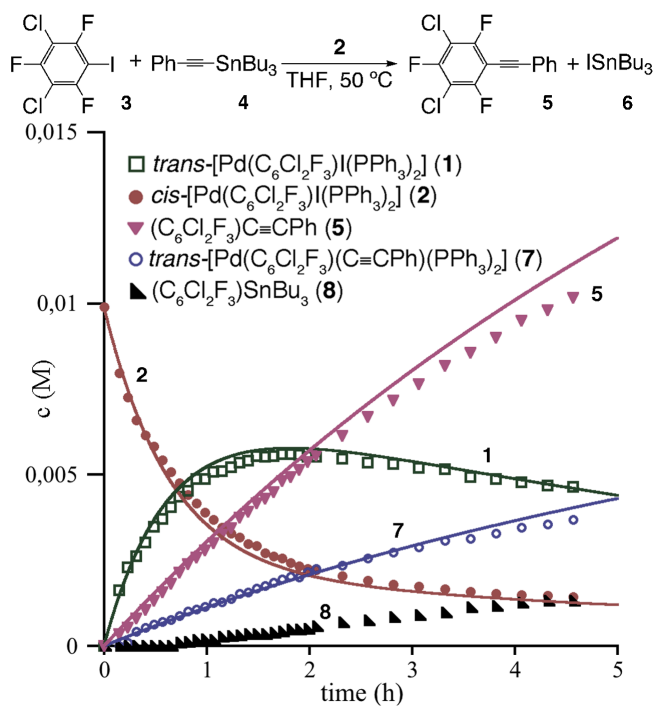

Figure 5. Concentration/time data for the reaction $\mathbf{3}+\mathbf{4}$, in THF at $323.2 \mathrm{~K}$, using $\mathbf{2}$ as initial catalyst. Note that the disappearance of $\mathbf{3}$ is not depicted and is out of the drawing limits.

The increasingly complicated view of the mechanisms of transition metal catalysis that these studies uncover is briefly summarized in Scheme 4. This Scheme is in fact deceptively simple, considering that it does not specify the several possible mechanisms of isomerization,,$^{28,30}$ of transmetalation, and of reductive elimination (for instance with or without $\mathrm{L}$ dissociation) hidden behind single arrows. In a more detailed mechanistic scheme, isomerization connections between cis and trans isomers should be also drawn attending to the fact that Pd complexes at different points in the cycle (as highlighted in Scheme 2) do isomerize at variable rates. Side reactions should also be considered. Full representation of all these complications would convert the cycles in a useless nightmare, and they are let out of the picture, but these competitive reactions do exist and have to be kept in mind when using the simplified mechanistic information in Scheme 2.

\section{Scheme 4. Mechanisms Usually Involved in Metal Cata- lyzed Reactions}

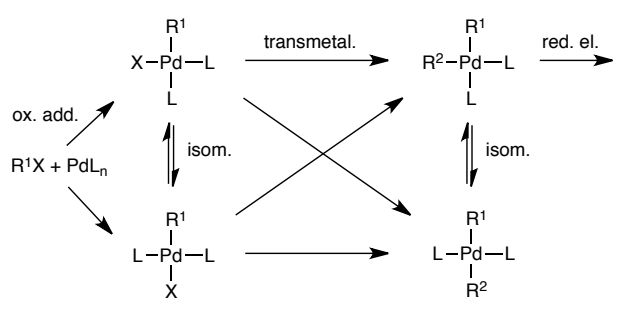

It is obvious from the picture just discussed that any attempt to generalize palladium catalyzed cross-coupling reactions by a simple reaction profile connecting data from different studies, or to assign in a general way the rate determining step (or state) to a single moment of the reaction, ${ }^{13 \mathrm{c}}$ is not realistic. Moreover, it is important to be aware that the kinetic behavior in multiequilibria systems existing in a running process is not a simple matter, as well as be conscious that the different steps can be influenced and complicated by other species present in solution that in principle do not pertain to the specific step under consideration. 
A way to simplify the complexity of the system is to prevent the formation of isomers, which might be achieved by using chelating ligands that force cis geometry or, in a more powerful way, by using bulky ligands that hinder the coordination of a second ancillary ligand and drive the cycle via functionally tri-coordinated $\mathrm{Pd}^{\mathrm{II}}$ complexes. Chelating hemilabile ligands and halo-bridged dimeric complexes might also offer easy access to 3-coordination. These possibilities are discussed later. But before doing that, and notwithstanding our comment in the previous paragraph, we will make some practical quick revision of what is known for the fundamental steps of Scheme 2. For more details and bibliography please refer to our 2004 review.

1) Oxidative addition: The oxidative addition of aryl iodide works easily on $\mathrm{Pd}^{0}$ complexes with good donor ligands, such as phosphines, but bromides work worse and chlorides or triflates usually fail. $\mathrm{Pd}^{0}$ complexes with less donor ligands such as $\mathrm{AsPh}_{3}$ fail even with ArI and need the addition of chloride to form anionic $\left[\mathrm{PdClL}_{2}\right]^{-}$complexes easier to oxidize. Complexes with good donor bulky phosphines are more reactive and their $\mathrm{Pd}^{0}$ complexes often react with the difficult chloride and triflate electrophiles, so that oxidative additions with aryl chlorides, triflates, tosylates, mesilates, pirazolylsulfonates, fluoroarylsulfonates, etc., have been reported in the last decade. ${ }^{31}$

2) Transmetalation: The cyclic mechanism requires a good bridging anionic ligand (typically a halide), and an easily leaving ligand (e.g. $\mathrm{AsPh}_{3}$, furyl phosphine) will give faster transmetalation. ${ }^{8}$ Free phosphine (e.g. from oxidation of $\left.\left[\mathrm{Pd}\left(\mathrm{PPh}_{3}\right)_{4}\right]\right)$ is very detrimental but can be sequestered with $\mathrm{CuX}$ salts. ${ }^{28}$ More electronegative halides accelerate the transmetalation because they make a more electrophilic $\mathrm{Pd}^{\mathrm{II}}$ center, ${ }^{32}$ and alkaline or alkylamonium salts can be used to promote in situ halide exchange. Stannatranes are interesting reagents for the transmetalation of $\mathrm{sp}^{3}$ carbons, because the $\mathrm{N}$ coordination to $\mathrm{Sn}$ increases the nucleophilicity of the reagent (see later)..$^{33,34}$

The open and ionic mechanisms are favored for bad coordinating anionic ligands (e.g. triflate), which create highly electrophilic Pd centers leading to fast transmetalation. The counteranion is often totally or partially displaced by even moderately coordinating solvents, such as THF, producing a more electrophilic cationic $\mathrm{Pd}^{\mathrm{II}}$ center and inducing the ionic mechanism in Scheme 2. More strongly coordinating and dissociating solvents (e.g. HMPA) can also produce cationic $\mathrm{Pd}^{\mathrm{II}}$ centers by halide substitution, in which case obviously the cyclic mechanism, lacking a good bridging groups (e.g. halides) on Pd, will not operate. ${ }^{9}$

3) Reductive elimination: The reductive elimination, occurring through a three-member transition state $\mathrm{PdR}^{1} \mathrm{R}^{2}$, needs the two groups involved to be mutually cis, which requires isomerization for those products of transmetalation with trans sterochemistry. The activation energy of coupling obviously depends on the groups to be coupled, following the trend $\mathrm{Csp}^{3}-$ $\mathrm{Csp}^{3}>\mathrm{Csp}^{3}-\mathrm{Csp}^{2}>\mathrm{Csp}^{2}-\mathrm{Csp}^{2} ;^{35}$ so it looks that more electron rich carbons require higher activation energies, and strongly donor ancillary ligands might be expected to make the coupling more difficult. Moreover, non-symmetrical complexes ( $\left[\mathrm{PdR}^{1} \mathrm{R}^{2} \mathrm{~L}_{2}\right]$ ) have computed activation energies that are roughly the average between those of their symmetrical counterparts, ${ }^{35}$ although experimental evidence shows that coupling rates are faster for $\left[\mathrm{PdR}^{1} \mathrm{R}^{2} \mathrm{~L}_{2}\right]$ than for $\left[\mathrm{PdR}_{2}^{1} \mathrm{~L}_{2}\right]$ or $\left[\mathrm{PdR}_{2}^{2} \mathrm{~L}_{2}\right] .{ }^{36}$ Finally, coupling can occur on tetra-coordinated Pd complexes (including also complexes with chelating ligands), ${ }^{37}$ or require $\mathrm{L}$ dissociation previous to coupling.

The role of ancillary ligands on coupling has been thoroughly studied and quantified by DFT methods (B3LYP) supported with experimental kinetics (Table 1). ${ }^{38,39}$ In addition to the influence of the $\mathrm{R}$ groups $\left(\Delta \mathrm{G}^{\ddagger}\right.$ increased in the order vinyl < $\mathrm{Ph}<\mathrm{Me}$ ) the couplings in complexes with different ancillary ligands were computed, including the case with $\mathrm{L}=$ empty position, which represents the coupling in functionally tricoordinated Pd complexes formed by bulky ligands. The activation free energies for the reductive elimination follow, for all the $\mathrm{R}$ groups, the trend illustrated in Table 1 for the Me-Me coupling. Me-Me coupling from a tricoordinated complex $\left(\Delta \mathrm{G}^{\ddagger}=\right.$ $13.2 \mathrm{kcal} \mathrm{mol}^{-1}$ ) must be very fast. This is an advantageous circumstance for the use of bulky ligands. Most of the ancillary ligands lead to coupling in the tetracoordinated complex and show higher or much higher activation energies than for the tricoordinated cases, the higher for the better donor ligands.

Table 1. Computed Energy Barrier $\left(\Delta G^{\ddagger}, \mathrm{kcal} \mathrm{mol}^{-1}\right)$ for the Reductive Elimination of Me-Me Starting from the cis$\left[\mathrm{PdMe}_{2}\left(\mathrm{PMe}_{3}\right)(\mathrm{L})\right]$ Complexes

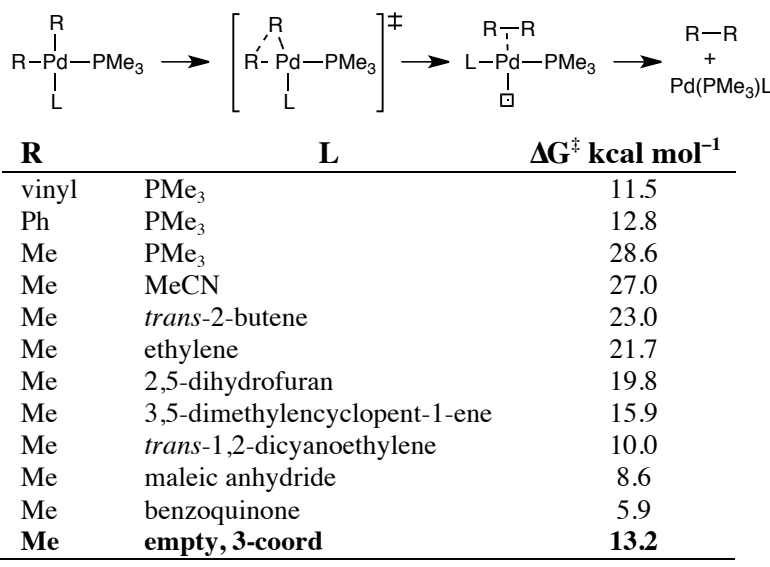

Interestingly, olefin ligands reduce dramatically the coupling barrier and strongly $\pi$-acceptor olefins lead to $\Delta \mathrm{G}^{\ddagger}$ values as low as $5.9 \mathrm{kcal} \mathrm{mol}^{-1}$ in the case of benzoquinone. This means that the difficult coupling of two Me groups in a complex coordinated with one $\mathrm{PMe}_{3}$ and one benzoquinone should be still very fast at temperatures of $-30{ }^{\circ} \mathrm{C}$ or lower. A support for this expectation was found in a recent study using a $\pi$ (electron withdrawing olefin) chelating ligand, where butane was formed quickly from Et groups at $-50{ }^{\circ} \mathrm{C}$. ${ }^{40}$ There are many reactions in the literature using as the initial catalyst $\left[\mathrm{Pd}(\mathrm{dba})_{2}\right]$ or $\left[\mathrm{Pd}_{2}(\mathrm{dba})_{3}\right]$ plus some added ligand. Since some $\mathrm{dba}$ is displaced after oxidative addition of $\mathrm{Pd}^{0}$ to $\mathrm{Pd}^{\mathrm{II}}$, these systems find, at the moment of coupling, the unexpected bonus that dba will contribute to reduce the coupling barrier. Of course at the cost of some increase in the oxidative addition barrier because electron-withdrawing olefins stabilize $\mathrm{Pd}^{0}$ against oxidation. ${ }^{7,41}$

\section{Ligands in Stille Coupling: Bulky Phosphines, Chelating} Ligands, Carbenes 
4.1. Bulky Phosphines. The use of electron rich bulky phosphine ligands should be regarded as a breakthrough in the development of effective protocols for challenging Stille cross-coupling reactions. $^{42}$ For instance, XPhos and $\left[\mathrm{Pd}(\mathrm{AcO})_{2}\right]_{3}$ accomplish the unprecedented Stille synthesis of biaryl compound from aryl mesylates and tosylates. ${ }^{43}$ Bulky electron-rich proazaphosphatrane $\mathrm{P}\left\{\left(\mathrm{R} / \mathrm{R}^{\prime}\right) \mathrm{NCH}_{2} \mathrm{CH}_{2}\right\}_{3} \mathrm{~N}$ $\left(\mathrm{R} / \mathrm{R}^{\prime}={ }^{i} \mathrm{Bu}, \mathrm{Bz}\right.$ ) ligands (Figure 6) are very efficient in the Stille coupling of electronically diverse aryl chlorides with a variety of organotin reagents, including sterically hindered systems. ${ }^{44}$

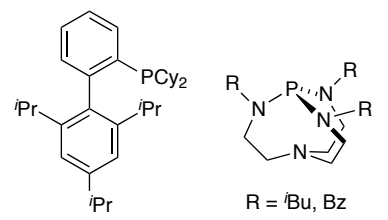

Figure 6. Structure of XPhos (left) and proazaphosphatrane (right).

In line with these results, the remarkable efficiency of $\mathrm{P}^{t} \mathrm{Bu}_{3}$ lead to the first effective Stille couplings of unactivated aryland vinyl-chlorides for the synthesis of a wide variety of products, including strongly hindered tetra-substituted biaryls, and Stille couplings of activated arylchlorides and unactivated arylbromides at room temperature. ${ }^{45}$ Another hint of the unique behavior of $\mathrm{P}^{t} \mathrm{Bu}_{3}$ was found in competition Stille experiments involving $\mathrm{ArCl} / \mathrm{Ar}$ 'OTf or $\mathrm{ClC}_{6} \mathrm{H}_{4} \mathrm{OTf}$ electrophiles, which revealed unexpected 43:1 selectivity for $\mathrm{Cl}-\mathrm{Ar}$ reaction over Ar-OTf. ${ }^{45}$ The same trend was found in Suzuki couplings ${ }^{46}{ }^{4}$ with the also unexpected selectivity for the coupling product of the aryl chloride over the aryl triflate (Figure 7). In contrast, the expected selectivity towards the triflate coupling product was obtained using $\mathrm{PCy}_{3}$ (cone angles $170^{\circ}$ ) instead of the bulkier $\mathrm{P}^{t} \mathrm{Bu}_{3}\left(\right.$ cone angle $\left.182^{\circ}\right){ }^{47}$

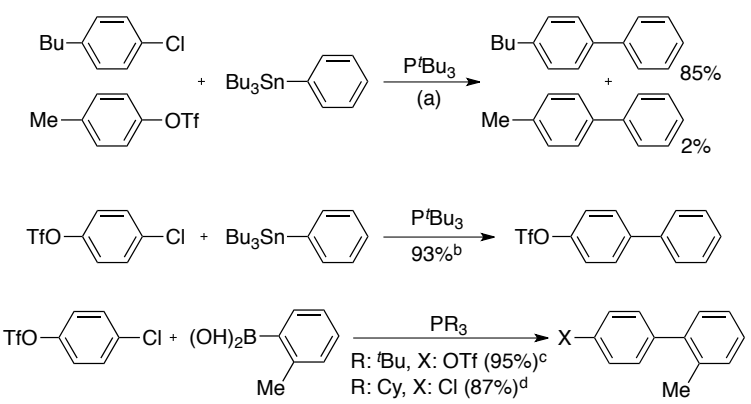

Figure 7. Inter- and intramolecular $\mathrm{Cl} / \mathrm{OTf}$ competition experiments in Stille and Suzuki couplings. (a) $1.5 \%\left[\mathrm{Pd}_{2}(\mathrm{dba})_{3}\right], 3.6 \%$ $\mathrm{P}^{t} \mathrm{Bu}_{3}, 2.2 \mathrm{CsF}$, dioxane, $60{ }^{\circ} \mathrm{C}$; (b) $0.75 \%\left[\mathrm{Pd}_{2}(\mathrm{dba})_{3}\right], 1.5 \%$ $\mathrm{P}^{t} \mathrm{Bu}_{3}, 2.2 \mathrm{CsF}$, dioxane, r.t.; (c) $1.5 \%\left[\mathrm{Pd}_{2}(\mathrm{dba})_{3}\right], 3 \% \mathrm{P}^{t} \mathrm{Bu}_{3}$; (d) $3 \%\left[\mathrm{Pd}_{2}(\mathrm{dba})_{3}\right], 6 \% \mathrm{PCy}_{3}$.

These experimental results, whether obtained from intermolecular or from intramolecular chloride/triflate competitions, along with computational studies, ${ }^{48,13 f}$ suggest that the different chemo- or regioselection occurs at the oxidative addition step and is determined by features of the $\mathrm{Pd}^{0}$ species such as the nucleophilicity of the ligands, the number of L ligands, their spatial requirements, their electric charge (neutral or anionic), and the polarity of the solvent. Accordingly, the more electron rich bisligated $\left[\mathrm{Pd}^{0} \mathrm{~L}_{2}\right]$ complex $\left(\mathrm{L}=\mathrm{PCy}_{3}\right)$ shows higher reactivity towards $\mathrm{Ar}-\mathrm{OTf}$, while the monoligated $\left[\mathrm{Pd}^{0} \mathrm{~L}\right](\mathrm{L}=$ $\left.\mathrm{P}^{t} \mathrm{Bu}_{3}\right)$ is more reactive towards $\mathrm{Ar}-\mathrm{Cl}$ affording [PdArClL], although this selectivity also depends on other reaction conditions, such as the polarity of the solvent (higher polarity favors reaction of the triflate), or the presence of additives. ${ }^{49}$

In a more general approach it has been shown, combining gas phase experiments in a ion-trap mass spectrometer and DFT calculations, that monoligated $\left[\mathrm{Pd}\left(\mathrm{PAr}_{2} \mathrm{Ar}{ }^{\prime}\right)\right]$ complexes have lower activation energies for oxidative addition of $\operatorname{ArX}(\mathrm{X}=$ $\mathrm{F}, \mathrm{Cl}, \mathrm{Br}, \mathrm{I})$ than bisligated $\left[\mathrm{Pd}\left(\mathrm{PAr}_{2} \mathrm{Ar}{ }^{\prime}\right)_{2}\right]$. These activation energies increase quite steeply depending on the halide, in the order $\mathrm{I}<\mathrm{Br}<\mathrm{Cl}<\mathrm{F}^{50}$

Three different pathways have been proposed to explain the oxidative addition of $\operatorname{ArX}(\mathrm{X}=\mathrm{Cl}, \mathrm{Br}, \mathrm{I})$ to $\left[\mathrm{Pd}^{0} \mathrm{~L}_{2}\right]$ complexes having phosphine ligands with different steric demands (Scheme 5): ${ }^{51}$ a) Oxidative addition of $\mathrm{ArX}$ by direct reaction with $\left[\mathrm{PdL}_{2}\right]$; b) Oxidative addition of $\mathrm{ArX}$ after associative displacement of $\mathrm{L}$ from $\mathrm{PdL}_{2}$; c) Oxidative addition of $\mathrm{ArX}$ after dissociation of $\mathrm{L}$ from $\left[\mathrm{PdL}_{2}\right]$. Apparently it is the nature of the halide that determines the mechanism experimentally observed, regardless of the bulkiness of the phosphine. Thus, ArI are active enough to react irreversibly with the less active $\left[\mathrm{PdL}_{2}\right]$ via associative displacement of a phosphine (pathway b). In contrast, the lower reactivity of $\mathrm{ArCl}$ requires a dissociative mechanism to afford a more reactive monoligated [PdL] on which oxidative addition takes place (pathway c). As for $\mathrm{ArBr}$, the major pathway is proposed to follow an irreversible reaction with $\left[\mathrm{PdL}_{2}\right]$ following either a displacement of one $\mathrm{L}$ (pathway b) or a direct oxidative addition (pathway a), but a minor not well defined dissociative pathway (pathway c) seems to be also operating. Depending on the size of the phosphine the tri-coordinated kinetic product will dimerize to the corresponding halo-bridged dimer.

\section{Scheme 5. Mechanisms for the Oxidative Addition of ArX to $\left[\operatorname{Pd}^{0} \mathbf{L}_{2}\right]$ Complexes}

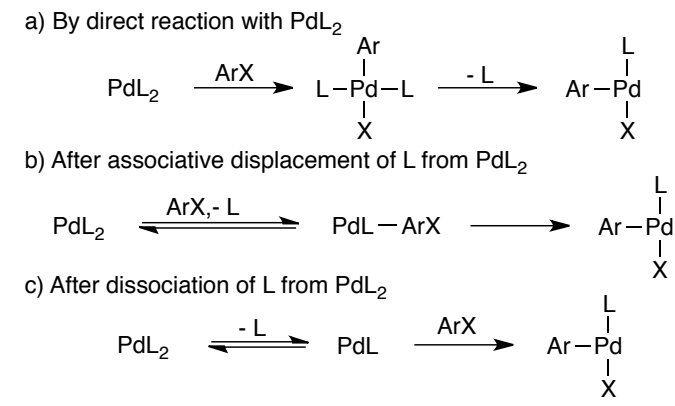

DFT studies on the oxidative addition of $\mathrm{PhCl}$ to $\left[\mathrm{Pd}\left(\mathrm{PR}_{3}\right)_{2}\right](\mathrm{R}$ $\left.=\mathrm{Me}, \mathrm{Et},{ }^{i} \mathrm{Pr},{ }^{t} \mathrm{Bu}\right)$ suggest that the oxidative addition step occurs, in all cases, on monoligated species $\left[\mathrm{Pd}\left(\mathrm{PR}_{3}\right)\right]$ (as in pathway $\mathrm{c}$ in Scheme 5). This activation energy for the transition state where $\mathrm{Ar}-\mathrm{Cl}$ interacts with the $\mathrm{Pd}^{0}$ complex is much higher on the bisligated complex. Interestingly the values of $\Delta \mathrm{G}_{\text {ox }}^{\ddagger}$ are almost identical regardless of the bulkiness of the phosphine, but the oxidation takes place only for the bulky $\mathrm{P}^{t} \mathrm{Bu}_{3} .{ }^{52}$ The reason for this must be that the preequilibrium dissociation of one phosphine is less unfavorable for bulky phosphine ligands, which increases their concentration under the conditions used in catalysis as compared to the smaller phosphines, affording kinetically effective concentrations that are not reached with the small phosphines, hence producing acceptable rates for the oxidation process. ${ }^{53,54}$

Tricoordinated $\mathrm{Pd}^{\mathrm{II}}$ complexes with bulky ligands are key intermediates in cross-coupling reactions. Calculations using 
$\left[\mathrm{PdPh}\left(\mathrm{NH}_{2}\right)\left(\mathrm{PH}_{3}\right)\right]$ as a model complex clearly support the Tshaped geometry bearing the more $\sigma$-donor aromatic ligand trans to the vacant site as the most stable structure.$^{55}$ The strict consideration of these complexes as 14-electron tricoordinated $\operatorname{Pd}(\mathrm{II})$ complexes can be questioned: ${ }^{55}$ the vast majority of them show $\mathrm{C}-\mathrm{H},{ }^{56}$ or other weak ${ }^{57,58}$ agostic coordination to the hypothetically empty coordination position on $\mathrm{Pd}$, and there is room for debate in certain cases, ${ }^{59}$ but a few examples with amide ligands look really tricoordinated. ${ }^{60}$ However, due to the strong $\pi$-donating ability of the lone pair in the amide nitrogen, these tricoordinated complexes cannot be said to be 14-electron. ${ }^{61}$ Agostic interactions can be easily dissociated at very low energy cost and lead to short-lived tricoordinated intermediates with an empty low-lying Pd orbital. As a consequence, these weakly protected Pd complexes can, for short, be considered in the discussions as operationally tricoordinat$e d$ for short . Their chemistry is dramatically different because they favor $16 \mathrm{e}-14 \mathrm{e}-16 \mathrm{e}$ dissociative mechanism over the most common 16e-18e-16e associative substitution operating in usual square planar Pd(II) complexes. ${ }^{21}$ Reductive elimination is favored in these tricoordinated complexes with electron rich phosphines bearing bulky substituents, such as $\mathrm{P}^{t} \mathrm{Bu}_{3} .{ }^{62}$ These phosphines happen to be electron rich, but they facilitate the coupling because they are bulky, not because they are electron rich. We have commented previously that electron-rich ligands making the $\mathrm{Pd}^{\mathrm{II}}$ center more electron rich should be detrimental for coupling because this increases the electron density on the carbons to be coupled, making their interaction more difficult. Yet the electron richness of $\mathrm{Pd}^{\mathrm{II}}$ with only three ligands (one phoshine) is less than with four ligands and obviously this facilitates the $\mathrm{C} \cdots \mathrm{C}$ interaction towards coupling. This consideration may also help to understand the influence of bulky phosphines on facilitation of coupling in the best recent challenging coupling, which is the formation of ArF by reductive elimination from $[\mathrm{PdArFL}](\mathrm{L}=$ BrettPhos $) .^{58}$

There are many electron rich bulky phosphines available to use and they have revolutionized the field of cross coupling processes. In fact, they are great assets to every step of the catalytic cycle, as illustrated by the simple sketch in Scheme 6 .

\section{Scheme 6. Sketch of the Performance of Bulky Phosphines} in the Elementary Steps in Cross-Coupling Reactions

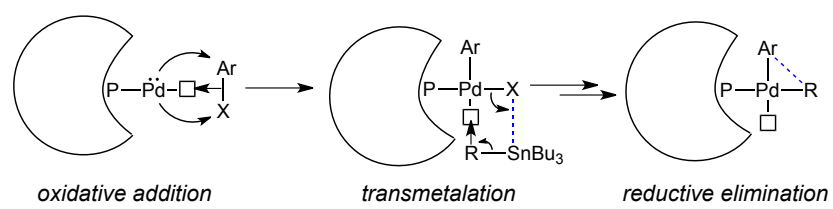

At the oxidative addition step a monoligated $\mathrm{Pd}^{0}$ structure offers an open space, fairly free of ligand repulsions, which facilitates the initial side-on approach of the $\mathrm{Ar}-\mathrm{X}$ bond to $\mathrm{Pd}$ (a nucleophilic attack to Pd by the electron pair of that bond); the electron richness of the phosphine provides efficient electron back-donation to the $\sigma^{*} \mathrm{Ar}-\mathrm{X}$ orbital, so that the oxidative addition is completed even for reagents with very low nucleophilicity of the Ar-X bond. At the transmetalation step the nucleophilic attack of the stannane occurs on a tricoordinated Pd center, which is always more electrophilic that an equivalent tetracoordinated center with one additional donor ligand. This facilitates the reaction with less strong tin nucleophiles. It is worth commenting that tricoordination at transmetalation is particularly beneficial for the Stille (and presumably for the Hiyama) processes because of the low nucleophilicity of tin derivatives due to the low polarity of the $\mathrm{Sn}-\mathrm{C}$ bond and the high volume of the tin reagent as compared to $\mathrm{Zn}, \mathrm{B}$ and other derivatives. Moreover, the $\mathrm{S}_{\mathrm{N}} 2$ transmetalation does not require the displacement of a leaving group (there is no need to pay for the displacement of the fourth ligand, inexistent or being at most an agostic interaction or the bridge in a dimer). As an extra bonus, the problem associated to the formation of cis and trans isomers that we have discussed somewhere else, does not exist in tricoordinated complexes. Finally, at the reductive elimination step tricoordinated complexes have very low coupling barriers (in the order of $13 \mathrm{kcal} \mathrm{mol}^{-1}$ for Me-Me coupling as discussed before). It is the combination of these virtues that makes the electrophilic bulky phosphines almost unbeatable for Stille processes, was not it for their high prices and their sensitivity to oxidation.

4.2. Chelating and Pincer Ligands. Chelating ligands could be thought of as an alternative cheaper solution to the problem of undesired isomers, as they force in Pd the cis geometry required for the final cross coupling. However, since early times, ${ }^{63}$ the few scattered studies report negative results,${ }^{64}$ with very rare exceptions. ${ }^{65}$ There are several possible reasons for the bad performance of diphosphines (PP). The diphosphines are difficult to dissociate and will stabilize tetracoordinated intermediates. Thus, they can sequester $\mathrm{Pd}^{0}$ in the form $\left[\mathrm{Pd}(\mathrm{PP})_{2}\right]$, very resistant to oxidation. They will also make difficult the transmetalation step because it often requires dissociation of one coordinated ligand to make room to the entering $\mathrm{R}^{2}$ coming with the tin reagent (Scheme 2 ). The same difficulty to release one end of a chelating ligand will also create a high activation barrier to reductive elimination. ${ }^{13 c, 66}$

Pd complexes with pincer ligands have been tried also in Stille reaction, and some of them have an extraordinary activity that will not be further discussed here because the catalysis is due to the formation of nanoparticles. ${ }^{67}$

4.3. Carbene ligands. Although very fashionable ligands in other fields (e.g. $\mathrm{Au}^{\mathrm{I}}$ catalysis), only rare examples of the use of an in situ prepared $\left[\mathrm{Pd}(\mathrm{OAc})_{2}\right]_{3} / \mathrm{NHC} \cdot \mathrm{HCl} / \mathrm{TBAF}$ system, ${ }^{68}$ or well defined trans-dihalo-palladium complexes bearing only one bulky NHC (nitrogen heterocyclic carbene) and a second easy leaving ligand, e.g. Pd-PEPPSI-Ipent, have proved effective in Stille cross-coupling. ${ }^{69}$ A recent review on these systems is available. ${ }^{70}$ In contrast, there are no synthetic reports using bis-carbene complexes and it has been nicely shown that the presence of two carbenes on Pd blocks the transmetalation step. ${ }^{71}$

\section{Stereoselectivity of Transmetalation: Inversion vs. Re- tention}

The double possibility to drive the transmetalation step of chiral stannanes taking advantage of the two conformational consequences of the cyclic (retention) and the open and ionic (inversion) pathways is an interesting possibility that seems not to have been consciously tested, but there are a few papers using chiral stannanes in the Stille reaction, which will be analyzed here in the light of the mechanistic possibilities in Scheme 2. The chiral stannanes used are easily accessible $\alpha$ heterosubstituted stannanes, except for the seminal work of Stille and the azastannatrane derivatives in Table 2. The use of chiral $\mathrm{C}\left(\mathrm{sp}^{3}\right) \alpha$-stannylated electrophiles affords insight into the transmetalation mechanism because the stereoselectivity of 
the whole reaction depends on this step, since the reductive elimination takes place with retention of the configuration at $\mathrm{sp}^{3}$ carbons. Thus, the stereochemistry found in the coupling products should report whether a cyclic or an open mechanism is operating. Table 2 gathers the reactions using as catalyst $\mathrm{Pd}$ exclusively, and a chiral stannane.

Table 2. Stereoselective Pd Catalyzed Stille Couplings

\begin{tabular}{|c|c|c|}
\hline chiral stannane & electrophile & $\begin{array}{c}\text { cat }(\mathbf{m o l} \%) \\
\text { solvent, } \mathbf{T}\left({ }^{\circ} \mathbf{C}\right) \\
\text { inversion } / \text { retention }\end{array}$ \\
\hline 3 & $\mathrm{Ph}_{\mathrm{Cl}} \stackrel{\mathrm{O}}{\mathrm{N}}$ & $\begin{array}{l}{\left[\mathrm{PdCl}\left(\mathrm{CH}_{2} \mathrm{Ph}\right)\left(\mathrm{PPh}_{3}\right)_{2}\right](4 \%)} \\
\mathrm{HMPA}, 65 \\
\geq \quad 65 \% \text { stereospecificity } \\
\text { inversion } * 72\end{array}$ \\
\hline & $\begin{array}{c}\mathrm{ArX} \\
\text { (X: I, Br) }\end{array}$ & $\begin{array}{l}{\left[\mathrm{Pd}\left(\mathrm{PPh}_{3}\right)_{4}\right](8 \%)} \\
\mathrm{DMF}, 60-75 \\
\text { complete inversion } \\
(90-94 \% \text { ee for different } \\
\text { aryls })^{73}\end{array}$ \\
\hline 3 & $\mathrm{PhI}$ & $\begin{array}{l}{\left[\mathrm{PdCl}_{2}(\mathrm{dppe})\right](10 \%)} \\
\mathrm{THF}, 45 \\
\text { complete retention } \\
(98 \% \text { ee })^{74} \\
{\left[\mathrm{PdCl}_{2}(\mathrm{dppe})\right](10 \%)} \\
\mathrm{THF}, 45 \\
\text { complete retention } * * 74\end{array}$ \\
\hline $\mathrm{OH}$ & $\mathrm{PhBr}$ & $\begin{array}{l}{\left[\mathrm{Pd}\left(\mathrm{PPh}_{3}\right)_{4}\right](5 \%)} \\
\text { dioxane, } 80 \\
\text { complete retention } \\
(99 \% \text { ee })^{75}\end{array}$ \\
\hline
\end{tabular}

*As indicated by Stille. **No ee data specified in the reference article, although the authors comment that complete retention of configuration is observed.

Retention of configuration in entries 3,4 might be expected since the conditions (less polar and not very coordinating solvents: e.g. THF, polar index: 4.0; dioxane, polar index: 4.8) are perfect for the oxidative addition product $\left[\mathrm{PdArXL}_{2}\right]$ to follow a cyclic transmetalation. In contrast, in the reactions in entries 1 and 2, partial or complete inversion is reported, as expected for an open mechanism, in spite of the fact that the presence of halide in the oxidative addition intermediate should also induce retention. The reason for this apparent contradiction is found in the effect of solvents on the $\left[\mathrm{PdArXL} \mathrm{L}_{2}\right]$ complexes. As shown in the cases in Table 3, better coordinating polar solvents as HMPA, NMP, and presumably DMF, are able to displace the halide ligand from $\left[\mathrm{PdArXL} L_{2}\right]$ to give a more electrophilic cationic complex and drive the reaction via the ionic pathway in Scheme 2, which implies inversion of configuration. Interestingly, in his seminal paper Stille found major but only partial inversion in HMPA, which fits well with the mixture of covalent and ionic species found in HMPA for a related $\mathrm{Pd}^{\mathrm{II}}$ complex in the conditions of Stille $(\mathrm{n}=0)$, suggesting competition of cyclic and ionic mechanisms.

Table 3. Speciation of Palladium Complexes in Different Conditions

$\underset{\substack{Y-P d \\ L}}{\stackrel{L}{L}-R^{1}+n L \stackrel{\text { solvent }}{\underset{L=P_{2}}{\longrightarrow}} \text { complexes }}$ in solution

Y solvent $n \quad$ complexes in solution

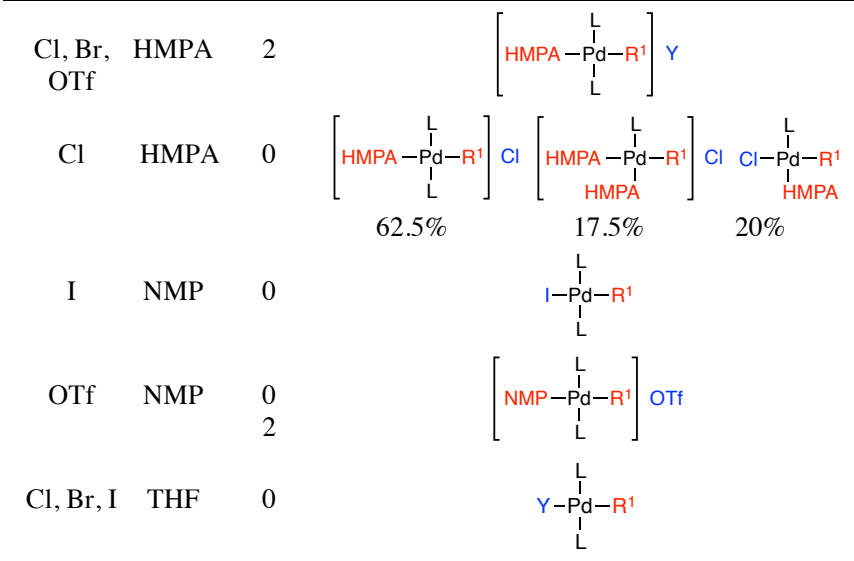

The scope of enantioselective Stille cross-coupling has been widened by the use of copper(I) salts as cocatalysts, which can play two different roles. It has been demonstrated that cooper salts can act as ligand scavengers mitigating the autoretardation by free phosphine of the rate-determining associative transmetalation (for instance when $\left[\mathrm{PdL}_{4}\right]$ is used as catalyst).$^{76}$ In this case the copper salt should not participate in the catalytic cycle and this copper effect does not lead to any difference in the stereochemical outcome. However, the copper effect may have another component, based on the existence of $\mathrm{Sn} / \mathrm{Cu}$ transmetalation processes. In fact, copper salts alone are able to catalyze Stille-like cross-coupling reactions without the assistance of palladium (Table 4). All the examples of palladium-free copper catalyzed Stille-like reactions found in the literature course with retention and are believed to operate via a $\mathrm{Cu}^{\mathrm{I}} / \mathrm{Cu}^{\mathrm{III}}$ cycle similar to the $\mathrm{Pd}^{0} / \mathrm{Pd}^{\mathrm{II}}$ classic Stille cycle. ${ }^{77}$ It is risky and premature to accept the $\mathrm{Cu} / \mathrm{Pd}$ comparison, or to take these findings as a general behavior, because all the reactions tested have been carried out in relatively low polar solvents and all the stannanes bear an oxygen substituent at $\alpha-C$.

Table 4. Stereoselective Cu Catalyzed Stille Couplings

\begin{tabular}{|c|c|c|}
\hline Chiral stannane & Electrophile & $\begin{array}{c}\text { Cat }(\mathbf{m o l} \%) \\
\text { solvent, } \mathbf{T}\left({ }^{\circ} \mathrm{C}\right) \\
\text { inversion /retention }\end{array}$ \\
\hline $\mathrm{SnBu}_{3}$ & $\overline{\overline{\mathrm{R}}}$ & $\begin{array}{l}\text { CuTC }(5-20 \%) \\
\text { dioxane, } 100 \\
\text { retention } *^{78}\end{array}$ \\
\hline & ' = triis & $\begin{array}{l}\text { CuTC }(20 \%) \\
\text { dioxane, } 90 \\
\text { retention*79 }\end{array}$ \\
\hline & & $\begin{array}{l}\mathrm{Cu}_{2} \mathrm{~S}(8 \%) \\
\mathrm{THF}, 70 \\
\text { retention*80 }\end{array}$ \\
\hline & & $\begin{array}{l}\mathrm{CuCN}(7 \%) \\
\mathrm{THF}, 50 \\
\text { retention } * 81\end{array}$ \\
\hline $\mathrm{Bu}_{3}$ & $\begin{array}{l}\text { Allyl, vinyl, } \\
\text { aryl halides }\end{array}$ & $\begin{array}{l}\mathrm{CuCN}(8 \%) \\
\mathrm{THF}, 45 \\
\text { retention*82 }\end{array}$ \\
\hline
\end{tabular}




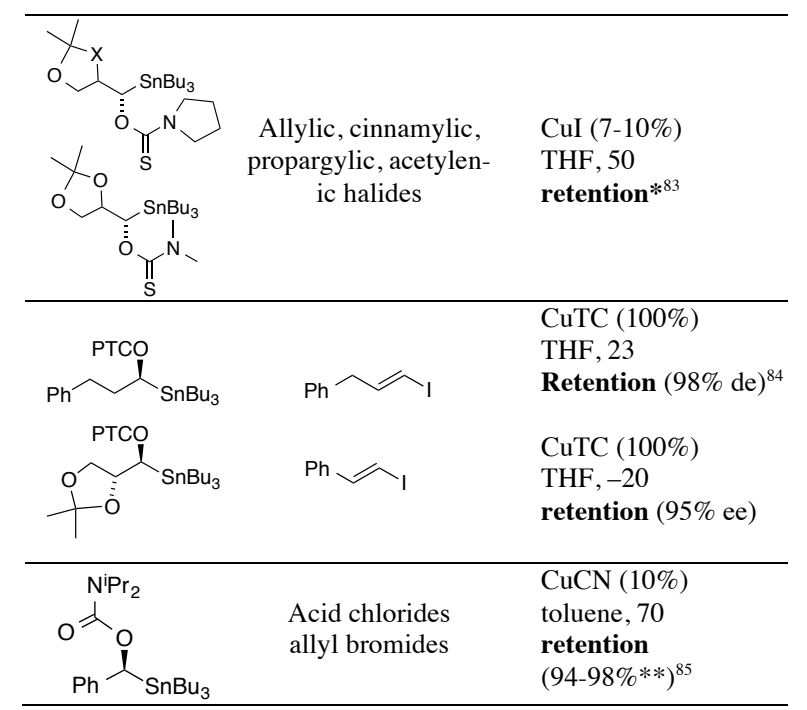

*No $e e$ data is specified in the reference article but the authors comment that complete retention of configuration is observed. ** Stereoselectivity value.

Finally, Table 5 collects reactions using $\mathrm{Pd}$ as catalyst and $\mathrm{Cu}$ salts as cocatalysts. With the previous data in mind, the question is: does copper participate in a bimetallic $\mathrm{Pd} / \mathrm{Cu}$ catalysis? With just one exception, using a special ligand, all the articles report retention. An inspection of the reaction conditions shows that the ligand used is a phosphine, and the $\mathrm{Cu}$ salt is stoichiometric, $2: 1$, or higher $\mathrm{Cu}: \mathrm{Pd}$ ratio. This suggests that the reactions are operating with phosphine scavenging copper effect, which is known to have an accelerating effect. ${ }^{76}$ Whether the copper salt participates with palladium in a bimetallic catalytic cycle (as we will report later for gold) or is only $\mathrm{Cu}$ catalysis, or $\mathrm{Pd}$ catalysis, or both competing, cannot be ascertained with the data available because, under the conditions used, in all cases retention should be expected regardless of the mechanism.

Table 5. Stereoselective Pd/Cu Catalyzed Stille Couplings

\begin{tabular}{|c|c|c|}
\hline Chiral stannane & Electrophile & $\begin{array}{c}\text { Cat }(\mathrm{mol} \%) \\
\text { Solvent, T }\left({ }^{\circ} \mathrm{C}\right) \\
\text { inversion / retention }\end{array}$ \\
\hline $\mathrm{Bu}_{3}$ & & $\begin{array}{l}{\left[\mathrm{Pd}_{2}(\mathrm{dba})_{3}\right](5 \%)} \\
\mathrm{CuCN}(5-10 \%) \\
\text { TTMPP }(20 \%) \\
\text { toluene, } 70 \\
\text { inversion*64b }\end{array}$ \\
\hline $99 \%$ ee & & $\begin{array}{l}{\left[\mathrm{Pd}(\mathrm{dba})_{2}\right](5 \%)} \\
\mathrm{CuCl}(200 \%) \\
\mathrm{KF}(200 \%) \\
\text { JackiePhos }(10 \%) \\
\text { MeCN, } 60 \\
\text { retention }(96 \% \mathrm{ee})^{34} \\
\end{array}$ \\
\hline $94 \%$ ee & & $\begin{array}{l}{\left[\mathrm{Pd}(\mathrm{dba})_{2}\right](5 \%)} \\
\mathrm{CuCl}(200 \%) \\
\mathrm{KF}(200 \%) \\
\text { JackiePhos }(10 \%) \\
\text { MeCN, } 60 \\
\text { retention } \\
(91-92 \% \text { ee })^{34}\end{array}$ \\
\hline OBz & & $\begin{array}{l}{\left[\mathrm{PdCl}_{2}\left(\mathrm{PPh}_{3}\right)_{2}\right]} \\
(4.5 \%) \\
\text { CuCN }(10.5 \%) \\
\text { Toluene, } 70 \\
\text { retention }(99 \% \text { ee })^{75}\end{array}$ \\
\hline
\end{tabular}

\begin{tabular}{|c|c|c|}
\hline 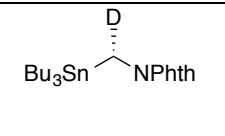 & 0 & $\begin{array}{l}{\left[\mathrm{Pd}\left(\mathrm{PPh}_{3}\right)_{4}\right](4 \%)} \\
\text { CuCN }(8 \%) \\
\text { Toluene, } 75 \\
\text { retention }(98 \% \text { ee })\end{array}$ \\
\hline NPhth & $\mathrm{PhBr}$ & $\begin{array}{l}{\left[\mathrm{PdCl}_{2}\left(\mathrm{PPh}_{3}\right)_{2}\right](8 \%)} \\
\mathrm{CuCN}(16 \%) \\
\text { dioxane, } 90 \\
\text { retention }(52 \% \text { ee })\end{array}$ \\
\hline JPhth & $\mathrm{PhBr}$ & $\begin{array}{l}{\left[\mathrm{PdCl}_{2}\left(\mathrm{PPh}_{3}\right)_{2}\right](8 \%)} \\
\mathrm{CuCN}(16 \%) \\
\text { toluene, } 90 \\
\text { retention }(69 \% \text { ee })\end{array}$ \\
\hline $\mathrm{Bu}_{3}$ & & $\begin{array}{l}{\left[\mathrm{PdCl}_{2}\left(\mathrm{PPh}_{3}\right)_{2}\right](4 \%)} \\
\mathrm{CuCN}(8 \%) \\
\text { toluene, } 95 \\
\text { retention*86 }\end{array}$ \\
\hline$\frac{\mathrm{OR}}{\mathrm{O}} \mathrm{SnBu}_{3}$ & & $\begin{array}{l}{\left[\mathrm{PdCl}_{2}(\mathrm{dppf})\right](8 \%)} \\
\mathrm{CuCN}(8 \%) \\
\text { toluene, } 90 \\
\text { retention*65a }\end{array}$ \\
\hline $\begin{array}{c}\mathrm{CH}_{3}\left(\mathrm{CH}_{2}\right)_{6} \\
\curlywedge_{94}^{\mathrm{OBz}} \mathrm{ee}\end{array}$ & & $\begin{array}{l}{\left[\mathrm{PdCl}_{2}\left(\mathrm{PPh}_{3}\right)_{2}\right](4 \%)} \\
\mathrm{CuCN}(8 \%) \\
\text { toluene, } 75 \\
\text { retention*87 }\end{array}$ \\
\hline
\end{tabular}

* No ee data is specified in the reference article but the authors comment that complete inversion/retention of configuration is observed.

\section{Bimetallic Pd/Au Stille catalysis}

Bimetallic catalysis refers here to catalytic protocols that use two different metals in two catalytic cycles usually connected by a transmetalation step (this excludes tandem processes). This field has been recently reviewed ${ }^{88}$ The potential of the bimetallic $\mathrm{Au} / \mathrm{Pd}$ pair has been evaluated in different conditions in a model Stille reaction between $p-\mathrm{CF}_{3} \mathrm{C}_{6} \mathrm{H}_{4} \mathrm{I}$ and $\mathrm{Bu}_{3} \mathrm{SnAr}$, in which transmetalation is the rate-determining step ${ }^{89}$ What we want to comment here, the effect of gold cocatalysis, can be illustrated by the selected reactions in Table 6: a dramatic beneficial effect of the presence of gold is noted as the bulkiness of the Ar group to be transmetalated increases. This clearly points to a mechanistic change. Note that in the reactions studied $\mathrm{Pd}$ and $\mathrm{Au}$ use the same $\mathrm{AsPh}_{3}$ ligand, and are added as fully coordinated complexes, so any potential ligand scavenging by gold (as observed in the copper effect by $\mathrm{Cu}^{\mathrm{I}}$ salts) is excluded.

\section{Table 6. Stille Au Co-Catalyzed Reactions}

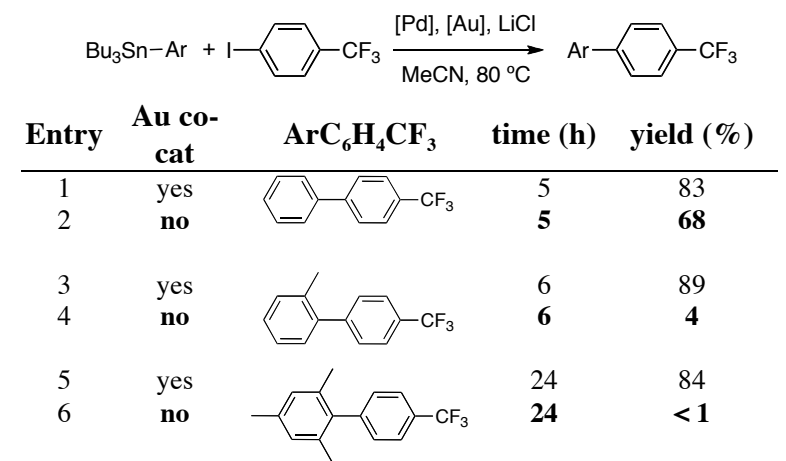




$\begin{array}{llll}7 & \text { yes } \\ 8 & \text { no } & 24 & 90 \\ & 24 & <1\end{array}$

These couplings could probably be carried out efficiently using bulky phosphines, but the co-catalized reaction is interesting because it shows very clearly one side of the Achilles heel of the classical Stille transmetalation: bulky groups are difficult to transmetalate due to their low nucleophilicity, originated in the low polarity of the $\mathrm{Sn}-\mathrm{C}$ bonds, but severely worsened by the steric hindrance when two $\mathrm{Pd}^{\mathrm{II}}$ and $\mathrm{Sn}^{\mathrm{IV}}$ compounds each with four ligands have to come close to each other in the transmetalation transition state. This steric problem is alleviated in the $\mathrm{Sn}^{\mathrm{IV}}$ to $\mathrm{Au}^{\mathrm{I}}$ transmetalation because $\mathrm{Au}^{\mathrm{I}}$ is linear, and also in the subsequent $\mathrm{Au}^{\mathrm{I}}$ to $\mathrm{Pd}^{\mathrm{II}}$ transmetalation. ${ }^{90}$ Quantitative values for this sequential $\mathrm{Sn} / \mathrm{Au} / \mathrm{Pd}$ double transmetalation of a 2-Me-naphtyl group, leading to the product in Table 6 , entry 7 via gold co-catalyzed Stille coupling were obtained by DFT methods and are shown in Scheme 7 and in Figure 8. The activation energy in $\mathrm{MeCN}$ for the $\mathrm{Sn} / \mathrm{Pd}$ transmetalation is $36.6 \mathrm{kcal} \mathrm{mol}^{-1}$, which in practice means a forbidden pathway. The other two transmetalations, $\mathrm{Sn} / \mathrm{Au}\left(25.5 \mathrm{kcal} \mathrm{mol}^{-1}\right)$ and $\mathrm{Au} / \mathrm{Pd}\left(21.4 \mathrm{kcal} \mathrm{mol}^{-1}\right)$ indicate a somewhat slow but perfectly feasible process.

\section{Scheme 7. DFT Calculated Pathway for the Sn to Au Transmetalation}
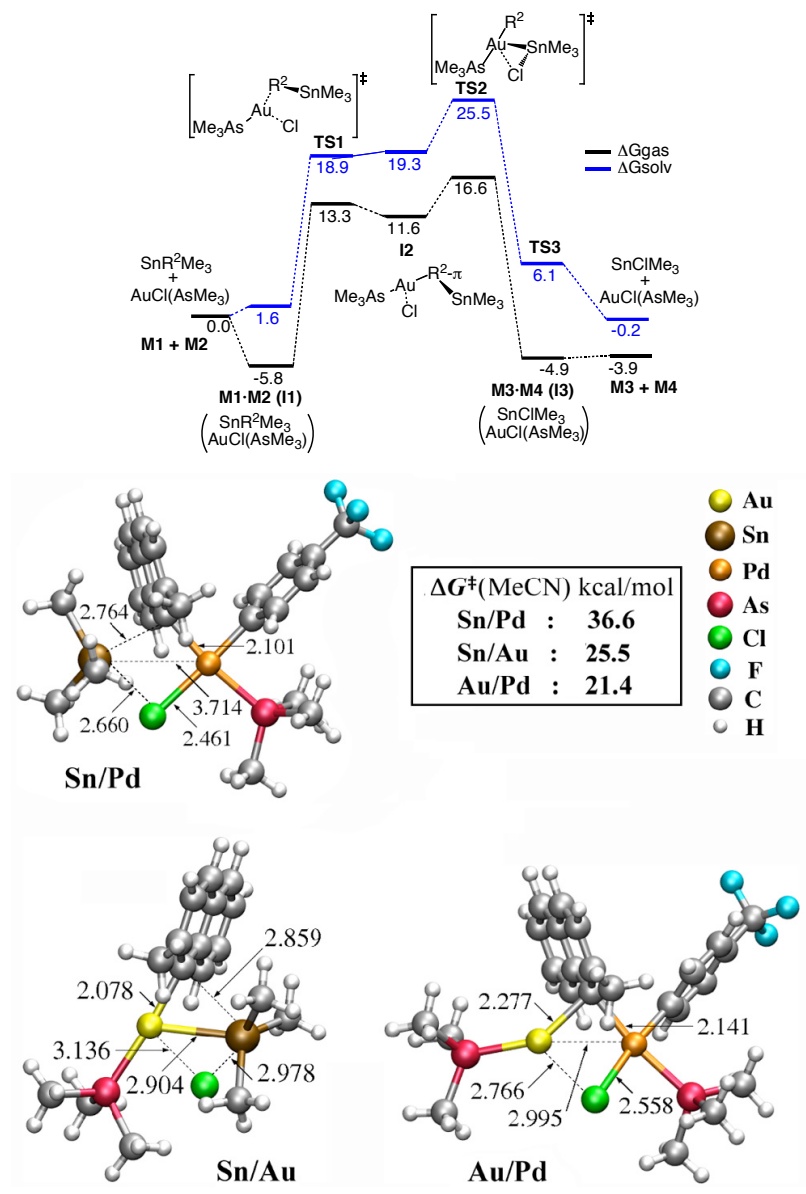

Figure 8. Transition states and $\Delta \mathrm{G}^{\ddagger}$ for thetransmetalations $\left(\mathrm{R}^{1}=\right.$ $p-\mathrm{CF}_{3} \mathrm{C}_{6} \mathrm{H}_{4} ; \mathrm{R}^{2}=2-\mathrm{Me}$-1-naphtyl; $\mathrm{X}=\mathrm{Cl}$ ).
Scheme 8 depicts together the classic (black) and the Au cocatalyzed (pink) Stille cycles. The yields at identical reaction times observed in Table 6 indicate that for simple aryls the two reaction rates are not very different (entries 1,2 ), but just one ortho substituent suffices to produce a large rate detriment, and two substituents make the classic Stille impossible, while the cocatalyzed version keeps running (entries 3-8).

Scheme 8. Classic and Co-Catalyzed Stille Processes $\left(\Delta G^{\dagger}\right.$ values are for the coupling in Fig. 8).

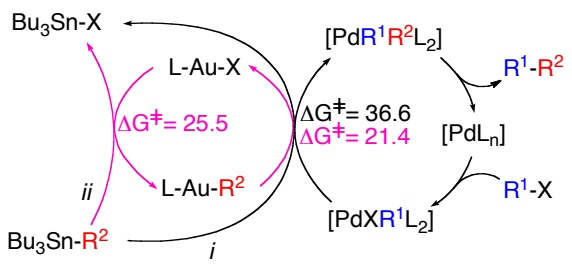

The optimization with synthetic purposes of one of the precedent reactions (between $p-\mathrm{CF}_{3} \mathrm{C}_{6} \mathrm{H}_{4} \mathrm{I}$ and $\mathrm{Bu}_{3}$ SnMes with a gold cocatalyst) supplied very interesting information about the decisive role of ligands in the classic and in the $\mathrm{Au} \mathrm{co-}$ catalyzed Stille reaction (Table 7). ${ }^{71}$ Using the same donor in both catalysts, $\mathrm{AsPh}_{3}$ and $\mathrm{PPh}_{3}$ give active catalyst, faster the first (entry 1) and slower but better protector against decomposition the second (entry 2). In dramatic contrast, the carbene ligand IDM blocks the catalysis (entry 3 ). The result in entry 4 demonstrates that it is the $\mathrm{Pd}$ complex $\left[\mathrm{PdCl}_{2}(\mathrm{IDM})_{2}\right]$ which is blocking the catalysis because at transmetalation $\mathrm{Pd}$ needs at least one easy leaving ligand; in entry $4, \mathrm{AsPh}_{3}$ plays this role of easy leaving ligand and the catalysis works perfect. As we had suggested before, this experiment proofs that two carbenes on $\mathrm{Pd}$ are incompatible with transmetalation in mild conditions. In [AuCl(IDM)], IDM does not disturb the catalysis because $\mathrm{Au}$ does not need to release $\mathrm{L}$ during the transmetalation (at their transition states $\mathrm{Au}$ is tri- or tetracoordinated and does not release any ligand). Having in mind that the ligands can scramble between metals until they find their preferred coordination site and this scrambling can be fast or slow, a judicious and appropriate choice of the ligand-metal pairs is necessary in bimetallic catalysts, in order to start with the best combination.

Table 7. Effects of the Different Ligands in the Initial Pd and Au Cocatalysts for a Stille Reaction

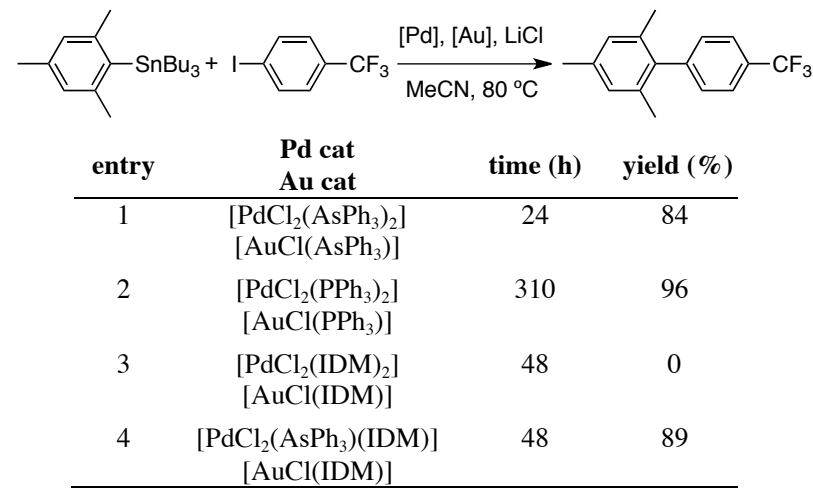

\section{Research towards greener Stille processes}

The classic and most extended routine procedure to remove most of organotin by-products is washing off the organic phase with an aqueous solution of potassium fluoride and 
filtration of the insoluble organotin fluoride. However, the washed product can still contain about $5 \%$ weight of tin. ${ }^{91}$ The concern about the toxicity of tin derivatives has lead to pursue several ideas to face the problem. These can be classified in four main approaches: $i$ ) catalytic use of stannanes; ii) use of polymer immobilized stannanes; iii) ionic-liquid-supported and phosphonium-supported Stille reactions; $i v$ ) utilization of molecular stannanes fully recyclable, or less toxic. Since some reviews are available $\mathrm{e}^{13 \mathrm{~d}, 92}$ we will comment only on the main lines to approach the problem.

i) Catalytic use of stannanes. This is a most interesting idea, although of limited application so far: as the formation of the tin transmetalating agent is a consequence of the hydrostannation of an alkyne, the scope of this reaction, catalytic in tin, is limited to the coupling of vinyl substrates (Scheme 9). ${ }^{93}$ The regeneration of tin (whether molecular or polymer supported) is based in the use of polymethylhydrosiloxane (PMHS) with or without added $\mathrm{KF},{ }^{94}$ to produce $\mathrm{R}_{3} \mathrm{SnH}$, which reacts with the alkyne to give a vinyl stannane. In fact this approach initially developed by Maleczka, is using also the benefits of other protocols discussed below, and affords values of tin contamination in the range 5-60 ppm. ${ }^{95}$

\section{Scheme 9. Tin Catalytic Stille Cross-Coupling}

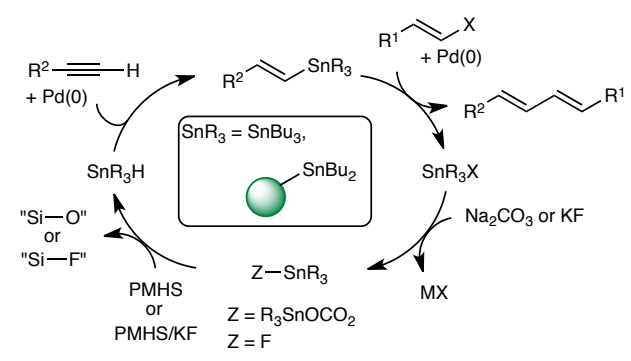

ii) Use of polymer immobilized stannanes. A common strategy to handle contaminant molecules is to support them in polymers. ${ }^{13 \mathrm{~d}}$ As far as leaching is not a problem, this approach offers an easy way to recover and, in some cases, recycle the contaminant reagent. This method was initially applied by Kuhn and Newmann, ${ }^{96}$ and later beautifully elaborated by Nicolaou into an intramolecular process leading to the synthesis of $(S)$-zearalenone. ${ }^{97}$

Immobilized polystyrene vinyl or phenyl stannanes have been successfully used in Stille cross-coupling reactions with aryland heteroaryl-halides. ${ }^{98}$ In the case of phenyl stannanes, treatment of the used polymer with 2,4,6-tri-mercapto-striazine (to remove the palladium deposit in the polymer after the first cycle) followed by a reaction with $\mathrm{PhMgBr}$ allowed for regeneration and recycling of the polymer but useful lasted no more than 4 cycles. ${ }^{98 \mathrm{~b}}$

More tunable, stannylated polymers with different solubilities ranging from quite soluble to insoluble have been recently obtained by direct vinylic polymerization or copolymerization of norbornene-type stannylated monomers. Some of these polymers are recyclable reagents in the Stille reaction (Scheme 10). ${ }^{99}$ The manipulations along the cycle, depending on the solubility or insolubility of the product in step B, are indicated in the scheme. Some reactions have been tested for recyclability up to 6 times, with yields dropping only from $81 \%$ in the first run to $69 \%$ in the sixth run, and tin contamination is down to $15-50 \mathrm{pm}$ with the insoluble polymer. ${ }^{100}$
Scheme 10. Recycling of Stannylated Polynorbornenes Reagents in Stille Cross-Coupling Reactions

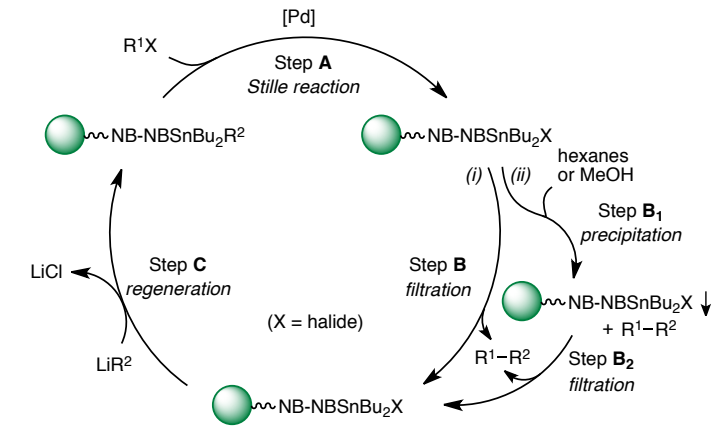

iii) Ionic-liquid-supported and phosphonium-supported Stille reactions. Similar to the polymer supported tin reagents, ionic liquid supported ${ }^{101}$ and phosphonium supported ${ }^{102}$ tin reagents (Figure 9) have been prepared and used in the Stille crosscoupling. Their use is aimed, as discussed for the case of polymers, at facilitating the separation or recycling of the tin byproducts. Lowering of tin contents in the coupling products to values lower than $3 \mathrm{ppm}$ is achieved.
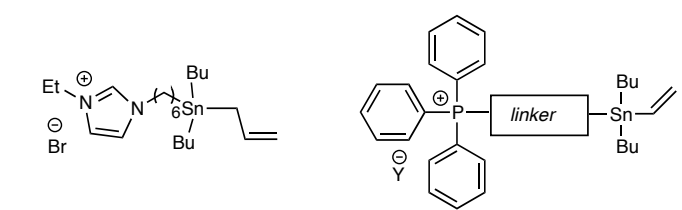

ionic liquid supported organotin reagent triarilphosphonium supported organotin reagent

Figure 9. Ionic liquid or phosphonium supported vinylstannanes.

iv) Utilization of fully recyclable, or less toxic molecular stannanes. Azastannatranes are very interesting tin reagents: on the one hand, $\mathrm{N}$ coordination to $\mathrm{Sn}$ increases the nucleophilicity of the reagent; ${ }^{33,34}$ on the other, protocols have been developed that allow for complete separation and recycling of the tin byproduct. A well known application was reported by Merck chemists in the synthesis of an anti-MethicillinResistant Staphylococcus Aureus (MRSA) carbapenem. ${ }^{103}$ Recently azastannatranes have been used for the $\mathrm{sp}^{3}-\mathrm{sp}^{2}$ Stille coupling of chiral secondary alkyls with aryl halides. Interestingly, the reactions occur with retention of configuration (Scheme 11)..$^{34}$

\section{Scheme 11. $\mathrm{sp}^{3}-\mathrm{sp}^{2}$ Stille coupling of chiral secondary al- kyls with aryl halides}

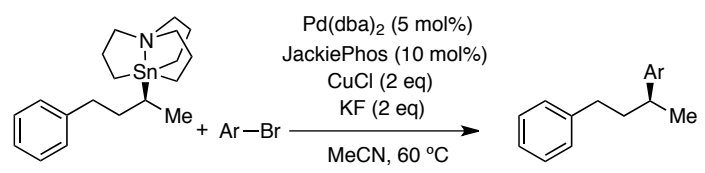

The use of less toxic but less reactive monoalkyl bisamido tin compounds derived from Lappert's stannylene $\mathrm{Sn}\left[\mathrm{N}\left(\mathrm{SiMe}_{3}\right)_{2}\right]_{2}$ is also interesting, because the coupling products are relatively free of tin contamination since the inorganic trifluorotin byproducts can be easily removed by simple filtration. The process has been applied in cross-coupling reactions with halides $^{104}$ and triflates ${ }^{105}$ with less than $1 \%$ of $\left[\mathrm{Pd}\left(\mathrm{PPh}_{3}\right)_{4}\right]$ or $\left[\mathrm{Pd}_{2}(\mathrm{dba})_{3}\right]^{106}$ using the protocol described in Scheme 12. It has been found that the best results are obtained under ligand-free conditions. ${ }^{106}$ 


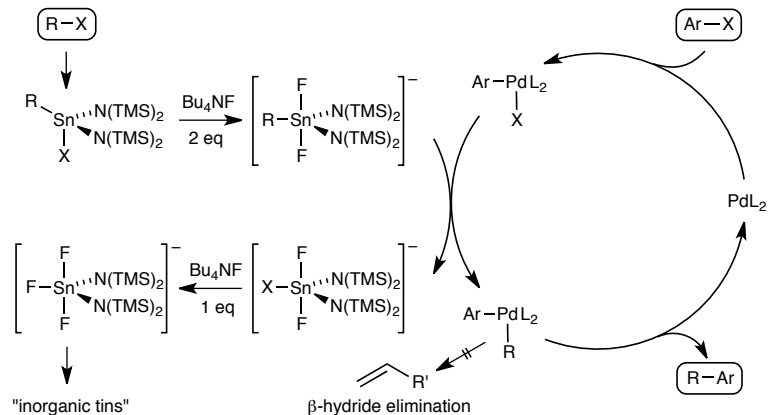

\section{CONCLUSION}

Thirty-eight years after its birth the Stille catalysis looks in good shape. We know now better how it works, what we can expect from it and what we should not. Stannanes keep being dependable reagents for delicate synthesis, and there are ways to heat up their sometimes too mild character (nucleophilicity) when needed. It is clear that just for this the Stille reaction is destined to have a permanent position in the cross-coupling team. But there are opportunities for other variations of the Stille process, and also some aspects that deserve more studies, particularly those related to enantioselectivity and control of toxicity. It will be interesting to see how far these items can be developed in the near future.

\section{ABBREVIATIONS}

VEGFR, Vascular Endothelial Growth Factor Receptors; Rf, 3,5-dichlorotrifluorophenyl; Pf, pentafluorophenyl; dba, dibenzylideneacetone; OTf, trifluoromethanesulfonate; BrettPhos, 2-(dicyclohexylphosphino)-3,6-dimethoxy-2',4',6'triisopropyl-1,1'-biphenyl; JackiePhos, 2-di[3,5bis(trifluoromethyl)phenylphosphino]-3,6-dimethoxy-2',4',6'triisopropyl-1,1'-biphenyl; HMPA, hexamethylphosphoramide; DMF, dimethylformamide; NMP, N-methy-2pyrrolidone; PTCO, pyrrolidinylthiocarbamoyl; CuTC, copper(I) thiophene-2-carboxylate; TTMPP, tris $(2,4,6$ trimethoxyphenyl)phosphine; dppf, 1,1bis(diphenylphosphino)ferrocene; NPhth, phthalimido derivative; IDM, 1,3-dimethyl-imidazol-2-ylidene; PMHS, polymethylhydrosiloxane; NHC, Nitrogen Heterocyclic Carbene.

\section{AUTHOR INFORMATION}

\section{Corresponding Author}

*Pablo Espinet, IU CINQUIMA/Química Inorgánica, Facultad de Ciencias, Universidad de Valladolid, 47071-Valladolid (Spain) Fax: (+)34 983 423013. E-mail: espinet@qi.uva.es http://gircatalisishomogenea.blogs.uva.es/.

\section{ACKNOWLEDGMENT}

The authors thank the Spanish MINECO (CTQ2013-48406-P) and the Junta de Castilla y León (GR 169 and VA256U13) for continued financial support.

\section{REFERENCES}

(1) Azarian, D.; Dua, S. S.; Eaborn, C.; Walton, D. R. M. J. Organomet. Chem. 1976, 117, C55-C75.

(2) (a) Kosugi, M.; Sasazawa, K.; Shimizu, Y.; Migita, T. Chem. Lett. 1977, 301-302. (b) Kosugi, M.; Shimizu, Y.; Migita, T. Chem. Lett. 1977, 1423-1424.

(3) Milstein, D.; Stille, J. K. J. Am. Chem. Soc. 1978, 100, 36363638.

(4) Memorials: (a) Hegedus, L. S. Organometallics 1990, 9, 30073008. (b) Lenz, R. W. Macromolecules 1990, 23, 2417-2418.

(5) Johansson Seechurn, C. C. C.; Kitching, M. O.; Colacot, T. J.; Snieckus, V. Angew. Chem., Int. Ed. 2012, 51, 5062-85.

(6) Stille J. K. Angew. Chem., Int. Ed.1986, 25, 508-524.

(7) Espinet, P.; Echavarren A. M. Angew. Chem., Int. Ed. 2004, 43, 4704-4734.

(8) Casado, A. L.; Espinet, P. J. Am. Chem. Soc. 1998, 120, 89788985

(9) Casado, A. L.; Espinet, P.; Gallego, A. M. J. Am. Chem. Soc. 2000, 122, 11771-11782.

(10) Casado, A. L.; Espinet, P.; Gallego, A. M.; Martínez-Ilarduya, J. M. Chem. Commun. 2001, 339-340.

(11) Selected books with chapters related to the Stille Reaction: (a) The Stille Reaction; Farina, V., Krishnamurthy, V., Scott, W. K.; Wiley: New York, 2004; originally published as Org. React. 1997, 50, 1-652. (b) Handbook of Functionalized Organometallics: Applications in synthesis; Knochel, P., Ed.; Wiley-VCH: Weinheim, 2005. (c) Metal-Catalyzed Cross-Coupling Reactions; Diederich, F., Stang. P. J., Eds.; Wiley-VCH: Weinheim, 2007. (d) Tin Chemistry: Fundamentals, Frontiers, and Applications; Davies, A. G., Gielen, M., Pannell, K. H., Tiekink, E. R. T., Eds.; Wiley: Chichester, 2008. (e) Computational Modeling for Homogeneous and Enzymatic Catalysis. A Knowledge-Base for Designing Efficient Catalysts; Morokuma, K., Musaev, D. G., Eds.; Wiley-VCH: Weinheim, 2008. (f) Applications of Transition Metal Catalysis in Drug Discovery and Development: An Industrial Perspective; Crawley, M. L., Trost, B. M., Eds.; Wiley: New Jersey, 2012. (g) Metal-Catalyzed Cross-Coupling Reactions and More; de Meijere, A., Bräse, S., Oestreich, M., Eds.; WileyVCH: Weinheim, 2014. (h) Copper-Mediated Cross-Coupling Reactions; Evano, G., Blanchard, N., Eds.; Wiley: New Jersey, 2014.

(12) Reviews on applied Stille reactions: (a) Carsten, B.; He, F.; Son, H. J.; Xu, T.; Yu, L. Chem. Rev. 2011, 111, 1493-1528. (b) Heravi, M. M.; Hashemi, E.; Azimian, F. Tetrahedron 2014, 70, 721.

(13) Selected reviews with relevant information about the Stille Reaction: (a) Nicolaou, K. C.; Bulger, P. G.; Sarlah, D. Angew. Chem., Int. Ed. 2005, 44, 4442-4489. (b) Barge, A.; Tagliapietra, S.; Tei, L.; Cintas, P.; Cravotto, G. Curr. Org. Chem. 2008, 12, 15881612. (c) Xue, L.; Lin, Z. Chem. Soc. Rev. 2010, 39, 1692-1705. (d) Albéniz, A. C.; Carrera, N. Eur. J. Inorg. Chem. 2011, 2347-2360. (e) Swift, E. C.; Jarvo, E. R. Tetrahedron 2013, 69, 5799-5817. (f) Bonney K. J.; Schoenebeck, F. Chem. Soc. Rev. 2014, 43, 6609-6638.

(14) Roughley, S. D.; Jordan, A. M. J. Med. Chem. 2011, 54, 3451-3479.

(15) (a) Young, D. In Tin Chemistry. Fundamentals, Frontiers, and Applications; Davies, A. G., Gielen, M., Pannell, K. H., Tiekink, E. R. T., Eds.; Wiley: Chichester, 2008; chap 5.8, pp 653-665. (b) Arakawa, Y.; Wada, O.; Yu, T. H. Toxicol. Appl. Pharmacol. 1981, 60, $1-7$.

(16) For an excellent review of transition metal-catalyzed carboncarbon cross-coupling reactions in the pharmaceutical industry see: Shen, H. C. In Applications of Transition Metal Catalysis in Drug Discovery and Development: An Industrial Perspective; Crawley, M. J., Trost, B. M., Eds.; Willey: New Jersey, 2012; chap 2, pp 25-95.

(17) Ragan, J. A.; Raggon, J. W.; Hill, P. D.; Jones, B. P.; McDermoot, R. E.; Munchhof, M. J.; Marx, M. A.; Casavant, J. M.; Copper, B. A.; Doty, J. L.; Lu, Y. Org. Process Res. Dev. 2003, 7, 676-683. 
(18) Stanetty, P.; Schnürch, M.: Mihovilovic, M. D. J. Org. Chem. 2006, 71, 3754-3761.

(19) "It is commonly believed, although one is hard-pressed to find unambiguous examples, that the selectivity of a reagent toward a series of reaction partners decreases as the reactivity of the reagent increases": Ritchie, C. D. Acc. Chem. Res. 1972, 5, 348-354.

(20) Johansson Seechurn, C. C. C.; Deangelis, A.; Colacot, T. J. In New Trends in Cross-Coupling: Theory and Applications; Colacot, T. J., Ed.; The Royal Society of Chemistry: Cambridge, 2015; chap 1, pp 4.

(21) Nova, A.; Ujaque, G.; Maseras, F.; Lledós, A.; Espinet, P. J. Am. Chem. Soc. 2006, 128, 14571-14578.

(22) Sosa Carrizo, E. D.; Fernández, I.; Martín, S. E. Organometallics 2015, 34, 159-166.

(23) The scope of the Stille reaction has been extended to the formation of C-heteroatom bonds. See, for instance: (a) Nishiyama, Y.; Sonoda, N. Mini-Rev. Org. Chem. 2005, 2, 147-155. (b) Uberman, P. M.; Lanteri, M. N.; Martín, S. E. Organometallics 2009, 28, 69276934.

(24) Napolitano, E.; Farina, V.; Persico, M. Organometallics 2003, $22,4030-4037$.

(25) Alvarez, R.; Faza, O. N.; López, C. S.; de Lera A. R. Org. Lett. 2006, 8, 35-38.

(26) For an example of dramatic changes in the predicted of activation energy for a simple ligand coordination process, upon selection of different functionals, see: Sieffert, N.; Bühl, M. Inorg. Chem. 2009, $48,4622-4624$.

(27) Pérez-Temprano, M. H.; Nova, A.; Casares, J. A.; Espinet, P. J. Am. Chem. Soc. 2008, 130, 10518-10520.

(28) Casado, A. L.; Espinet, P. Organometallics 1998, 17, 954 959.

(29) For cross-coupling methods with faster transmetalation this problem could not operate. 3683 .

(30) Casado, A. L.; Espinet, P. Organometallics 1998, 17, 3677-

(31) So, C. M.; Kwong, F. Y. Chem. Soc. Rev. 2011, 40, 49634972.

(32) Ariafard, A.; Lin, Z.; Fairlamb, I. J. S. Organometallics 2006, $25,5788-5794$. In this paper the transmetalation barrier increases in the order $\mathrm{Cl}<\mathrm{Br}<\mathrm{I}$ and it was related to the fact that down the group of $\mathrm{X}$ the $\mathrm{Sn}-\mathrm{X}$ bond energy decreases faster than the $\mathrm{Pd}-\mathrm{X}$ bond energy. This is a thermodynamic argument not valid for the kinetic observations. The reason we give in the text is a better explanation.

(33) (a) Jurkschat, K.; Tzschach, A. J. Organomet. Chem. 1984, 272, C13-C16. (b) Jurkschat, K.; Tzschach, A.; Meunier-Piret, J. J. Organomet. Chem. 1986, 315, 45-49. (c) Vedejs, E.; Haight, A. R.; Moss, W. O. J. Am. Chem. Soc. 1992, 114, 6556-6558.

(34) Li, L.; Wang, C.-Y.; Huang, R.; Biscoe, M. R. Nat. Chem. 2013, 5, 607-612.

(35) Ananikov, V. P.; Musaev, D. G.; Morokuma, K. Organometallics 2005, 24, 715-723.

(36) Hartwig, J. F. Inorg. Chem. 2007, 46, 1936-1947.

(37) Zuidema, E.; van Leeuwen, P. W. N. M.; Bo, C. Organometallics 2005, 24, 3703-3710.

(38) Pérez-Rodríguez, M.; Braga, A. A. C.; Garcia-Melchor, M.; Pérez-Temprano, M. H.; Casares, J. A.; Ujaque, G.; de Lera, A. R.; Álvarez, R.; Maseras, F.; Espinet, P. J. Am. Chem. Soc. 2009, 131, 3650-3657.

(39) The coupling of allyl groups has also been calculated: (a) Pérez-Rodríguez, M.; Braga, A. A. C.; de Lera, A. R.; Maseras, F.; Álvarez, R.; Espinet, P. Organometallics 2010, 29, 4983-4991. (b) Méndez, M.; Cuerva, J. M.; Gómez-Bengoa, E.; Cárdenas, D. J.; Echavarren, A. M. Chem.-Eur. J. 2002, 8, 3620-3628.

(40) Gioria, E.; Martínez-Ilarduya, J. M.; Espinet, P. Organometallics 2014, 33, 4394-4400.
(41) Fairlamb, I. J. S.; Kapdi, A. R.; Lee, A. F.; McGlacken, G. P.; Weissburger, F.; de Vries, A. H. M.; Schmieder-van de Vondervoort, L. Chem.-Eur. J. 2006, 12, 8750-8761, and references therein.

(42) García-Melchor, M.; Ujaque, G.; Maseras, F.; Lledós, A. In Phosphorus Compounds: Advanced Tools in Catalysis and Material Sciences, Vol. 37; Peruzzini, M., Gonsalvi, L., Eds.; Springer: Berlin, 2011; chap 3, pp 57-84.

(43) Naber, J. R.; Fors, B. P.; Wu, X.; Gunn, J. T.; Buchwald, S. L. Heterocycles 2010, 80, 1215-1226.

(44) (a) Su, W.; Urgaonkar, S.; Verkade, J. G. Org. Lett. 2004, 6, 1421-1424. (b) Su, W.; Urgaonkar, S.; McLaughlin, P. A.; Verkade, J. G. J. Am. Chem. Soc. 2004, 126, 16433-16439.

(45) Littke, A. F.; Schwarz, L.; Fu, G. C. J. Am. Chem. Soc. 2002, $124,6343-6348$

(46) Littke, A. F.; Dai, C.; Fu, G. C. J. Am. Chem. Soc. 2000, 122, 4020-4028.

(47) For cone angles see: Rahman, M. M.; Liu, H.-Y.; Eriks, K.; Prock, A.; Giering, W. P. Organometallics 1989, 8, 1-7.

(48) Schoenebeck, F.; Houk, K. N. J. Am. Chem. Soc. 2010, 132, 2496-2497.

(49) Proutiere, F.; Schoenebeck, F. Angew. Chem., Int. Ed. 2011 50, 8192-8195. (b) Proutiere, F.; Schoenebeck, F. Synlett 2012, 645648.

(50) Vikse, K.; Naka, T.; McIndoe, J. S.; Besora M.; Maseras, F. ChemCatChem 2013, 5, 3604-3609.

(51) Barrios-Landeros, F.; Carrow, B. P.; Hartwig, J. F. J. Am. Chem. Soc. 2009, 131, 8141-8154.

(52) Li, Z.; Fu, Y.; Guo, Q. X.; Liu, L. Organometallics 2008, 27, $4043-4049$.

(53) Christmann, U.; Vilar, R. Angew. Chem., Int. Ed. 2005, 44, $366-374$.

(54) The reaction rates are also a function of the concentration of the reagents, not only of $\Delta \mathrm{G}^{\ddagger}$. A process will not have an observable rate unless the critical reacting species reach a certain concentration (depending on $\Delta \mathrm{G}^{\ddagger}$ ). We call this a kinetically efficient concentration.

(55) Moncho, S.; Ujaque, G.; Lledós, A.; Espinet, P. Chem.-Eur. J. 2008, 14, 8986-8994.

(56) (a) Cámpora, J.; Gutiérrez-Puebla, E.; López, J. A.; Monge, A.; Palma, P.; del Río, D.; Carmona, E. Angew. Chem., Int. Ed. 2001 40, 3641-3644. (b) Takamiya, I.; Yamashita, M.; Nozaki, K. Organometallics 2008, 27, 5347-5352. (c) Sergeev, A. G.; Spannenberg, A.; Beller, M. J. Am. Chem. Soc. 2008, 130, 15549-15563. (d) Gauthier, D.; Lindhardt, A. T.; Olsen, E. P. K.; Overgaard, J.; Skrydstrup, T. J. Am. Chem. Soc. 2010, 132, 7998-8009. (e) Quesnel, J. S.; Arndtsen, B. A. J. Am. Chem. Soc. 2013, 135, 16841-16844.

(57) Fors, B. P.; Watson, D. A.; Biscoe, M. R.; Buchwald, S. L. J. Am. Chem. Soc. 2008, 130, 13552-13554.

(58) Watson, D. A.; Su, M.; Teverovskiy, G.; Zhang, Y.; GarcíaFortanet, J.; Kinzel, T.; Buchwald, S. L. Science 2009, 325, 16611664.

(59) Korsager, S.; Taaning, R. H.; Skrydstrup, T. J. Am. Chem. Soc. 2013, 135, 2891-2894.

(60) Yamashita, M.; Hartwig, J. F. J. Am. Chem. Soc. 2004, 126, $5344-5345$

(61) Moncho, S.; Ujaque, G.; Espinet, P.; Maseras, F.; Lledós, A. Theor. Chem. Acc. 2009, 123, 75-84.

(62) Roy, A. H.; Hartwig, J. F. Organometallics 2004, 23, 15331541 .

(63) Farina, V.; Krishnan, B. J. Am. Chem. Soc. 1991, 113, 95859595.

(64) (a) Fihri, A.; Meunier, P.; Hierso, J.-C. Coord. Chem. Rev. 2007, 251, 2017-2055. (b) Kells, K. W.; Chong, J. M. J. Am. Chem. Soc. 2004, 126, 15666-15667.

(65) (a) Belosludtsev, Y. Y.; Bhatt, R. K.; Falck, J. R. Tetrahedron Lett. 1995, 36, 5881-5882. (b) Gajare, A. S.; Jensen, R. S.; Toyota, 
K.; Yoshifuji, M.; Ozawa, F. Synlett 2005, 144-148. (c) Crawforth, C. M.; Burling, S.; Fairlamb, I. J. S.; Kapdi, A. R.; Taylor, R. J. K.; Whitwood, A. C. Tetrahedron 2005, 61,9736-9751.

(66) Senn, H. M.; Ziegler, T. Organometallics 2004, 23, 2980 2988.

(67) (a) Olsson, D.; Nilsson, P.; El Masnaouy, M.; Wendt, O. F. Dalton Trans. 2005, 1924-1929. (b) Bröring, M.; Kleeberg, C.; Köhler, S. Inorg. Chem. 2008, 47, 6404-6412.

(68) Grasa, G. A.; Nolan, S. P. Org. Lett. 2001, 3, 119-122.

(69) Dowlut, M.; Mallik, D.; Organ, M. G. Chem.-Eur. J. 2010, $16,4279-4283$.

(70) Valente, C; Calimsiz, S.; Hoi, K. H.; Mallik, D.; Sayah, M.; Organ, M. G. Angew. Chem., Int. Ed. 2012, 51, 3314-3332.

(71) delPozo, J.; Casares, J. A.; Espinet, P. Chem. Commun. 2013, 49, 7246-7248

(72) Labadie, J. W.; Stille, J. K. J. Am. Chem. Soc. 1983, 105, 669670 .

(73) Kalkofen, R.; Hoppe, D. Synlett 2006, 1959-1961.

(74) Goli, M.; He, A.; Falck, J. R. Org. Lett. 2011, 13, 344-346.

(75) Krizkova, P. M.; Hammerschmidt, F. Eur. J. Org. Chem. 2013, 5143-5148.

(76) Casado A. L.; Espinet, P. Organometallics, 2003, 22, 13051309.

(77) Wang, M.; Lin, Z. Organometallics 2010, 29, 3077-3084.

(78) Li, H.; He, A.; Falck, J. R.; Liebeskind, L. S. Org. Lett. 2011, $13,3682-3685$.

(79) Wang, R.; Falck, J. R. Org. Biomol. Chem. 2015, 13, 16241628.

(80) Falck, J. R.; Bhatt, R. K.; Reddy, K. M.; Ye, J. Synlett 1997, 481-482.

(81) Falck, J. R.; Barma, D. K.; Mohapatra, S.; Bandyopadhyay, A.; Reddy, K. M.; Qi, J.; Campbell, W. B. Bioorg. Med. Chem. Lett. 2004, 14, 4987-4990.

(82) Falck, J. R.; Bhatt, R. K.; Ye, J. J. Am. Chem. Soc. 1995, 117 5973-5982.

(83) Mohapatra, S.; Bandyopadhyay, A.; Barma, D. K.; Capdevila, J. H.; Falck, J. R. Org. Lett. 2003, 5, 4759-4762.

(84) Falck, J. R.; Patel, P. K.; Bandyopadhyay, A. J. Am. Chem. Soc. 2007, 129, 790-793; Correction: J. Am. Chem. Soc. 2008, 130, 2372-2372.

(85) Lange, H.; Fröhlich, R.; Hoppe, D. Tetrahedron 2008, 64, 9123-9135

(86) Ye, J.; Bhatt, R. K.; Falck, J. R. Tetrahedron Lett. 1993, 34, $8007-8010$

(87) Ye, J.; Bhatt, R. K.; Falck, J. R. J. Am. Chem. Soc. 1994, 116, $1-5$.

(88) Pérez-Temprano, M. H.; Casares, J. A.; Espinet P. Chem.Eur.J. 2012, 18, 1864-1884.

(89) delPozo, J.; Carrasco, D.; Pérez-Temprano, M. H.; GarcíaMelchor, M.; Álvarez, R.; Casares, J. A.; Espinet, P. Angew. Chem., Int. Ed. 2013, 52, 2189-2193.
(90) Pérez-Temprano, M. H.; Casares, J. A.; de Lera, A. R.; Álvarez, R.; Espinet, P. Angew. Chem., Int. Ed. 2012, 51, 4917-4920.

(91) Leibner, J. E.; Jacobus, J. J. Org. Chem. 1979, 44, 449-450.

(92) (a) Palladium-Catalyzed Coupling Reactions: Practical Aspects and Future developments; Molnár, A., Ed.; Wiley-VCH: Weinheim, 2013. (b) Chrétien, J.-M.; Kilburn, J. D.; Zammattio, F.; Le Grognec, E.; Quintard, J.-P. In Tin Chemistry: Fundamentals, Frontiers, and Applications; Davies, A. G., Gielen, M., Pannell, K. H., Tiekink, E. R. T., Eds.; Wiley: Chichester, 2008; pp 607-621. (c) Young, D. In Tin Chemistry: Fundamentals, Frontiers, and Applications; Davies, A. G., Gielen, M., Pannell, K. H., Tiekink, E. R. T., Eds.; Wiley: Chichester, 2008; pp 653-665.

(93) (a) Maleczka, R. E. Jr.; Gallagher, W. P.; Terstiege, I. J. Am. Chem. Soc. 2000, 122, 384-385. (b) Gallagher, W. P.; Terstiege, I.; Maleczka, R. E. Jr. J. Am. Chem. Soc. 2001, 123, 3194-3204.

(94) (a) Maleczka, R. E. Jr.; Gallagher, W. P. Org. Lett. 2001, 3, 4173-4176. (b) Gallagher, W. P.; Maleczka, R. E. Jr. J. Org. Chem. 2005, 70, 841-846.

(95) Hernán, A. G.; Guillot, V.; Kuvshinov, A.; Kilburn, J. D. Tetrahedron Lett. 2003, 44, 8601-8603.

(96) Kuhn, H.; Neumann, W. P. Synlett 1994, 123-124.

(97) Nicolaou, K. C.; Winssinger, N.; Pastor, J.; Murphy, F. Angew. Chem., Int. Ed. 1998, 37, 2534-2537.

(98) (a) Kerric, G.; Le Grognec, E.; Fargeas, V.; Zammattio, F.; Quintard, J.-P.; Biesemans, M.; Willem, R. J. Organomet. Chem. 2010, 695, 1414-1424. (b) Kerric, G.; Le Grognec, E.; Zammattio, F.; Paris, M.; Quintard, J.-P. J. Organomet. Chem. 2010, 695, 103-110.

(99) (a) Meana, I.; Albéniz, A. C.; Espinet, P. Adv. Synth. Catal. 2010, 352, 2887-2891. (b) Carrera, N.; Gutiérrez, E.; Benavente, R.; Villavieja, M. M.; Albéniz, A. C.; Espinet, P. Chem.-Eur.J. 2008, 14, 10141-10148. (c) Carrera, N.; Salinas-Castillo, A.; Albéniz, A. C.; Espinet, P.; Mallavia, R. J. Organomet Chem. 2011, 696, 3316-3321.

(100) Martínez-Arranz, S.; Carrera, N.; Albéniz, A. C.; Espinet, P.; Vidal-Moya, A. Adv. Synth. Catal. 2012, 354, 3551-3560.

(101) (a) Vitz, J.; Mac, D. H.; Legoupy, S. Green Chem. 2007, 9 431-433. (b) Louaisil, N.; Pham, P. D.; Boeda, F.; Faye, D.; Castanet, A.-S.; Legoupy, S. Eur. J. Org. Chem. 2011, 143-149.

(102) Poupon, J.-C.; Marcoux, D.; Cloarec, J.-M.; Charette, A. B. Org. Lett. 2007, 9, 3591-3594.

(103) Jensen, M. S.; Yang, C.; Hsiao, Y.; Rivera, N.; Wells, K. M.; Chung, J. Y. L.; Yasuda, N.; Hughes, D. L.; Reider, P. J. Org. Lett. 2000, 2, 1081-1084.

(104) (a) Fouquet, E.; Pereyre, M.; Rodriguez, A. L. J. Org. Chem. 1997, 62, 5242-5243. (b) Rodriguez, A. L.; Peron, G.; Duprat, C.; Vallier, M.; Fouquet, E.; Fages, F. Tetrahedron Lett. 1998, 39, 11791182.

(105) Fouquet, E.; Rodriguez, A. L. Synlett 1998, 1323-1324.

(106) Herve, A.; Rodriguez, A. L.; Fouquet, E. J. Org. Chem. 2005, 70, 1953-1956. 